Article

\title{
Impact of Electroosmosis and Wall Properties in Modelling Peristaltic Mechanism of a Jeffrey Liquid through a Microchannel with Variable Fluid Properties
}

\author{
Choudhari Rajashekhar ${ }^{1}(0)$, Fateh Mebarek-Oudina ${ }^{2}(0)$, Ioannis E. Sarris $3, *\left(\mathbb{D}\right.$, Hanumesh Vaidya ${ }^{4, *}$, \\ Kerehalli V. Prasad ${ }^{4}$, Gudekote Manjunatha ${ }^{5}$ and Hadimane Balachandra ${ }^{5}$ \\ 1 Department of Mathematics, Karnataka State Akkamahadevi Women's University, \\ Vijayapura 586108, Karnataka, India; choudhariraj3@gmail.com \\ 2 Department of Physics, Faculty of Sciences, University of 20 août 1955-Skikda, Skikda 21000, Algeria; \\ oudina2003@yahoo.fr \\ 3 Department of Mechanical Engineering, University of West Attica, 12244 Athens, Greece \\ 4 Department of Mathematics, Vijayanagara Sri Krishnadevaraya University, \\ Vijayapura 586108, Karnataka, India; prasadkv2007@gmail.com \\ 5 Department of Mathematics, Manipal Institute of Technology, Manipal Academy of Higher Education, \\ Manipal 576104, Karnataka, India; manjunatha.g@manipal.edu (G.M.); balachandrash@gmail.com (H.B.) \\ * Correspondence: sarris@uniwa.gr (I.E.S.); hanumeshvaidya@gmail.com (H.V.)
}

Citation: Rajashekhar, C.;

Mebarek-Oudina, F.; Sarris, I.E.;

Vaidya, H.; Prasad, K.V.; Manjunatha,

G.; Balachandra, H. Impact of

Electroosmosis and Wall Properties in

Modelling Peristaltic Mechanism of a

Jeffrey Liquid through a

Microchannel with Variable Fluid

Properties. Inventions 2021, 6, 73.

https://doi.org/10.3390/

inventions6040073

Academic Editors: Rahmat Ellahi and M. M. Bhatti

Received: 5 September 2021

Accepted: 26 October 2021

Published: 28 October 2021

Publisher's Note: MDPI stays neutral with regard to jurisdictional claims in published maps and institutional affiliations.

Copyright: () 2021 by the authors. Licensee MDPI, Basel, Switzerland. This article is an open access article distributed under the terms and conditions of the Creative Commons Attribution (CC BY) license (https:// creativecommons.org/licenses/by/ $4.0 /)$.
Abstract: The current work emphasizes the modelling of the electroosmosis-modulated peristaltic flow of Jeffery liquid. Such flows emerge in understanding the movement of biological fluids in a microchannel, such as in targeted drug delivery and blood flow through micro arteries. The non-Newtonian fluid flows inside a non-uniform cross-section and an inclined microchannel. The effects of wall properties and variable fluid properties are considered. The long wavelength and small Re number approximations are assumed to simplify the governing equations. Debye-Hückel linearization is also utilized. The nonlinear governing equations are solved by utilizing the perturbation technique. MATLAB is used for the solution, velocity, temperature, skin friction, coefficient heat transport, concentration, shear wood number, and streamlines expressions. The obtained result in optimal electroosmotic velocity (or Helmholtz-Smoluchowski velocity) increases from -1 to 6 ; the axial circulation has substantial momentum. For larger optimal electroosmotic velocity, a subsequent boost in an axial electric field causes a significant deceleration. Further, the study helps biomedical engineers to create biomicrofluidics devices that may aid in carrying biological fluids.

Keywords: electroosmosis; Debye length; peristaltic mechanism; skin friction; variable fluid properties; heat transfer coefficient

\section{Introduction}

In the human body, peristalsis is the reflex response initiated when lumen contents stretch the gut wall. It mainly occurs in all parts of the gastrointestinal tract, from the esophagus to the rectum. The primary role of the mechanism is to transport the fluids via a distensible tube facilitated by utilizing a progressive wave of expansion and contraction. The movement of food through the throat, chyme transport, urine conveyed through the ureter, ova transportation from the ovary to the uterus, liquid stream in ductus efferent, blood development from tiny blood conduits, and lymph transportation through the lymphatic vessels are some examples of peristalsis. Additionally, it is utilized for planning different contemporary clinical supplies, such as roller-finger siphons and siphoning of blood in the heart-lung machine. The earlier studies on peristaltic flow were carried out by taking Newtonian fluid. However, recent studies have been carried out by taking non-Newtonian fluids because of its broader application in complex structures. The work on Newtonian fluid was initiated by Latham [1] to investigate the peristaltic mechanism 
in the ureter for urine flow. After that, numerous studies have been conducted recently with taking non-Newtonian liquids in different geometrical assumptions. Inspired by this, the first investigation on peristalsis of a non-Newtonian fluid was carried out by Raju and Devanathan [2] using the power-law model. Manjunatha et al. [3] studied the slip effects on peristaltic transport of Casson fluid in an inclined elastic tube with porous walls. Furthermore, Vaidya et al. [4] investigated the rheological properties and peristalsis of Rabinowitsch fluid through compliant porous walls in an inclined channel. Their study shows that the Biot number increases the temperature for dilatant fluid, whereas it decreases for Newtonian and pseudoplastic fluids. In continuation of [4], Manjunatha et al. [5] studied the effects of wall properties on the peristaltic transport of Rabinowitsch fluid through an inclined non-uniform slippery tube. Their results show that an increase in the value of velocity and thermal slip parameters enhances the velocity and temperature profiles for viscous and shear-thinning fluids. Oudina et al. [6] investigated the entropy and convection effect on magnetized hybrid nano-liquid flow inside a trapezoidal cavity with a zigzagged wall. Their studies claim that magnetic field application strongly influences the flow of nanofluid, and the thermal performance of the cavity is improved with the augmentation of the Reynolds and Hartmann numbers. Furthermore, the statistical approach has been conducted on dual stratification on stagnation point Walter's B nanofluid via radiative Riga plate by Shafiq et al. [7].

In modelling biological liquids, the study of heat transfer characteristics plays an enormous role in understanding fluid behavior. The heat transfer in the body uses four heat exchange systems to maintain homeostasis: conduction, radiation, convection, and evaporation. These mechanisms rely on the property of heat to stream from a greater concentration to a lower concentration. Therefore, heat exchange mechanisms vary in rate according to the temperature level and conditions of the environment. Driven by the application, the heat transfer characteristics of the peristaltic mechanism through porous annulus were examined by Vajravelu et al. [8]. Srinivas and Kothandapani [9] scrutinized the heat transport characteristics of a peristaltic mechanism through an asymmetric channel. Ali et al. [10] scrutinized the impact of heat transport over peristaltic flow through a curved channel. Tanveer et al. [11] examined the heat transport characteristics of peristaltic flow through modified Darcy's law. Further, mass transfer is another essential factor in the scattering interaction, such as the dispersion of supplements from the blood to adjoining cells. In the more significant part of the modern applications, mass transfer assumes a huge role in understanding the cycles engaged with invert assimilation, film division measure, dissemination of synthetic pollutions, and refining measure. Different analysts have considered the impact of heat and mass transport by thinking about these cut off points with various numerical models [12]. Iftikhar et al. [13] studied the peristaltic flow of an Eyring Prandtl fluid in a diverging tube with heat and mass transfer. Their investigations have observed that the rate of heat transfers and mass transfers decreases with an increasing Grashof number. Magesh et al. [14] investigated the heat and mass transfer analysis on non-Newtonian fluid motion driven by peristaltic pumping in an asymmetrically curved channel. Numerical investigation of nonlinear radiation with magneto-micropolar stagnation point flow past a heated stretching sheet was done by Warke et al. [15]. Motivated by the above research, Rajashekhar et al. [16] investigated the effect of mass and heat transport impact on the peristaltic flow of Ree-Eyring liquid with variable properties for hemodynamic flow.

The elastic wall properties strongly affect the wavy fluid flow behavior regarding mean pressure, axial velocity, and net flow rate. These wall properties were articulated as a flexible wall model preserved through elastic spring to disperse the vertical wall displacement and wall damper to damp the average wall velocity. Consideration of wall properties in peristalsis is of unique value in the scrutiny of blood flow in arteries and veins, urine flow in the urethras, and airflow in the lungs. Moreover, investigations on the influence of wall properties and Poiseuille flow in peristalsis were done by Mittra and Prasad [17]. Further, Srinivas et al. [18] studied the effect of heat and mass transfer on 
MHD peristaltic flow through a porous space with compliant walls. The series solution for the axial velocity, temperature, and concentration distribution has been computed. Hayat et al. [19] investigated the peristaltic transport of viscous fluid in a curved channel with compliant walls. Eldesoky et al. [20] investigated the combined effect of heat transfer, complaint wall properties, and slip conditions on the peristaltic flow through a tube. Recently, Javed et al. [21] studied the peristaltic flow of a realistic fluid in a complaint channel.

The variable fluid properties (viscosity and variable conductivity) play an exceptional role in understanding blood flow in micro arteries. Most of the investigations carried out on peristalsis have considered the viscosity and thermal conductivity of the fluid to be constant. However, recent studies have shown the importance of considering the variable properties in investigating biological liquids. It can be noticed from the literature that the viscosity of the blood varies concerning the thickness and temperature. Nadeem et al. [22] modelled the peristaltic flow by considering the variation in viscosity concerning the thickness of the tube. Further, the impact of slip and variation in viscosity with a thickness on the peristaltic mechanism was investigated by Sinha et al. [23]. Further, Nadeem et al. [24] investigated the effects of temperature-dependent viscosity on the peristaltic flow of a Jeffrey-six constant fluid in a non-uniform vertical tube. The expressions for pressure rise, temperature, pressure gradient, and stream functions are sketched for various embedded parameters and interpreted in their study. However, recently, the variation of viscosity concerning thickness and thermal conductivity concerning temperature variations on the peristaltic flow of non-Newtonian fluids with different geometrical configurations was carried out by [25]. Vaidya et al. [26] studied the peristaltic motion of non-Newtonian fluid with variable liquid properties in a convectively heated non-uniform tube utilizing the Rabinowitsch fluid model. Chu et al. [27] analyzed the entropy analysis in the Rabinowitsch fluid model through the inclined wavy channel by considering both constant and variable properties. Their study shows that a small amount of entropy is observed at the bottom of the channel, and maximum entropy is noted at the ciliated walls under the effect of the Brinkman number. Rajashekhar et al. [28] studied the unsteady flow of Rabinowitsch fluid on peristaltic transport in a non-uniform channel with temperature-dependent properties. Vaidya et al. [29] studied the effect of variable liquid properties on the peristaltic flow of a Rabinowitsch fluid in an inclined convective porous channel with variable thermal conductivity. The study reveals that an increase in the value of porous parameters diminishes the occurrence of the trapping phenomenon for Newtonian and dilatant fluid models. Recently, Rajashekhar et al. [30] studied the peristalsis of Ree-Eyring fluid with homogeneous and heterogeneous reactions addressing hemodynamic applications.

Most of the above studies carried out on peristaltic transport were carried out in the absence of an electric field. However, it has considerable benefits in microfluidic pumping. It permits an effective policy of microchannel circulation areas employing electrical fields because it does not need the standard relocating components featured in traditional micropumps. Electroosmotic pumping has been observed to create a continual pulse-free circulation via applying an electrical field to an electrolyte in contact through an area. The viscous drag triggers the fluid to flow tangentially to the area and creates a consistent net migration of ions. The demand for quick, reputable, and reliable microfluidic systems has generated the strict need for tiny, easy-to-handle, and inexpensive analytic devices. Such applications consist of drug delivery, deoxyribonucleic acid (DNA) sequencing/analysis systems, and biological/chemical agent discovery sensors over integrated circuits. One of the most significant challenges in microfluidic transfer systems in a few of the above applications hinges on increasing the price of fluid circulation to the optimum possible limit through organizing for ideal mixes of flow activating mechanisms. On the other hand, electro-osmosis has ended up being a more straightforward mechanism to develop virtually plug-shaped velocity profiles in microchannels through manipulating the communication of an applied axial electrical field via the local fee density gradients close to the liquid-solid user interface. It has considerable benefits in microfluidic pumping and permits very reliable microchannel flow areas through electric fields. It does not call for 
the typical relocating elements included in conventional micro-pumps. Electroosmotic pumping has been examined to create a continual pulse-free flow. These pumps are also a lot more open to construction at the microscale. They are significantly being released in biomedical systems, such as medicinal distribution, plasma splitting, electro-osmotically activated bio-microfluidic systems, etc. Flow actuation is realized using an electric field with an electrolyte in contact through a surface. The connection of the surface area through the electrolyte causes a web charge thickness. The viscous drag causes the fluid to move tangentially to the area and creates a constant web movement of ions. Driven by the application of electroosmotic transport on the peristaltic device, Chakraborty [31] designed the peristaltic circulation by taking an electric field. Furthermore, detailed information about electroosmosis and nanopores has been mentioned in a textbook written by Bruus [32]. Ai et al. [33] analyzed and tested the porous membrane with platinum electrodes coated on both sides of a low-voltage nano-porous electroosmotic pump. Wu et al. [34] studied an alternating current electroosmotic pump based on conical nanopore membranes. Asandei et al. [35] investigated the electroosmotic trap against the electrophoretic force near a protein nanopore. Bengtsson and Robinson [36] presented an all-plastic, flexible electroosmotic pump constructed from commercially available materials with the help of an adjustable electroosmotic pump. Huang et al. [37] analyzed the electroosmotic capture and ionic discrimination of peptide and protein biomarkers with FraC nanopores. Chinappi et al. [38] investigated the analytical model for particle capture in nanopores, which elucidates competition among electrophoresis, electroosmosis, and dielectrophoresis. Talapatra and Chakraborty [39] investigated squeeze flow between charged parallel plates by taking an electric field. Later, Bandopadhyay [40] investigated the electroosmosis-modulated peristaltic transport in microfluidic channels. Waheed et al. [41,42] studied the heat and mass transfer in the electroosmosis flow of third-order fluid in the absence and presence of slip effects. Analysis of heat stream in electroosmotic bio-fluid flow in a straight microchannel via peristalsis was done by Noreen et al. [43]. Recently, Tripathi et al. [44] investigated the numerical simulation of double-diffusive convection and electroosmosis during peristaltic transport of a micropolar nanofluid on an asymmetric microchannel.

The mathematical model is developed to examine the electroosmosis modulated peristaltic flow of Jeffrey liquid via a non-uniform channel. The impact of the inclination angle with the horizontal under the effects of wall properties is considered. Further, the variation in viscosity and thermal conductivity are also taken into consideration. The present investigation is the first of its kind in considering the electroosmotic peristalsis of Jeffrey liquid in the presence of changeable liquid properties via a non-uniform inclined channel. The semi-analytical technique (perturbation method) is used to solve the governing nonlinear equations. Outcomes are presented graphically to explore the impact of the parameters emerging in the problem. The current work incorporates flow characteristics and thermal characteristics in the model, which will help stimulate drug delivery in circulatory systems.

\section{Physical Model}

Let us consider a 2D electrokinetic modulated flow of Jeffrey liquid through a nonuniform inclined microfluidic channel having half width $l(\bar{x})$. The propagation of sinusoidal waveforms thus flow at a continuous speed $c$ along the compliant channel walls (See Figure 1). Let $\bar{Y}= \pm \bar{h}(\bar{X}, \bar{t})$ be the upper and lower wall, respectively. Here, propagation of waves is along the axial direction $(x-$ axis). The heat and mass transport scrutiny are maintained through giving $T_{0}, C_{0}$ and $T_{1}, C_{1}$ to the inferior channel wall and the superior channel wall, respectively. It is assumed that the electric field $E$ is required axially for the liquid circulation. 


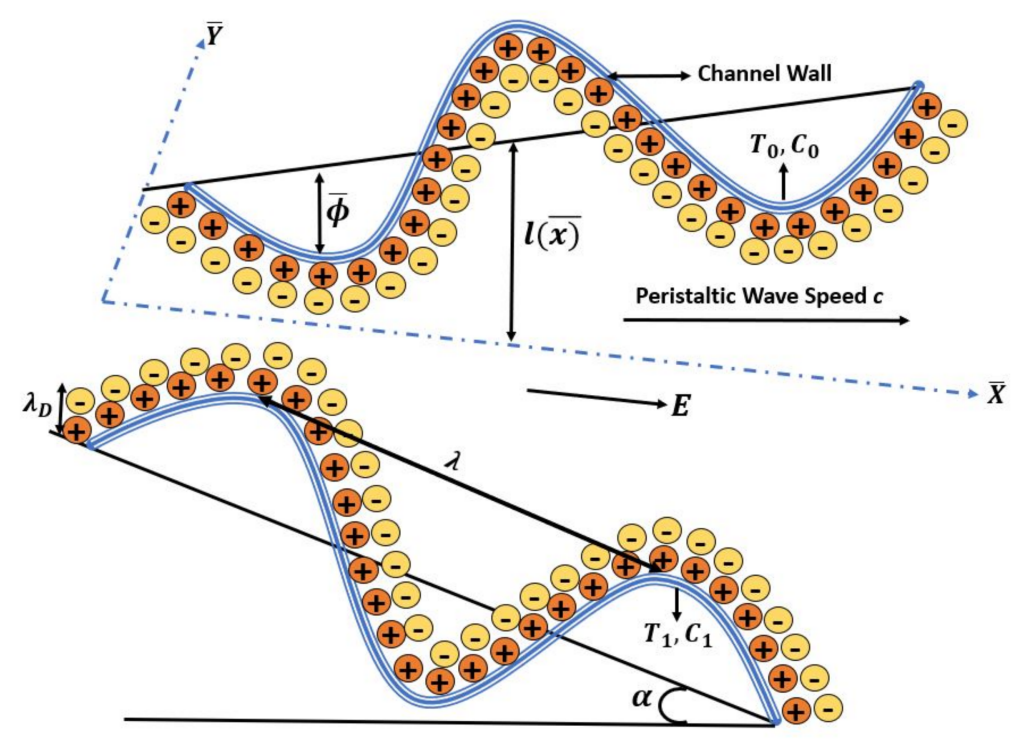

Figure 1. Flow channel configuration.

The microchannel wall equation is given by [14]:

$$
\bar{Y}=\bar{h}(\bar{X}, \bar{t})=l(\bar{x})+\bar{b} \sin \left[2 \pi \frac{(\bar{X}-c \bar{t})}{\lambda}\right],
$$

where $l(\bar{x})=a_{0}+\bar{K} \bar{x}$.

The governing equation in the laboratory frame of reference for the circulation of Jeffrey liquid in electrohydrodynamics (EHD) are

$$
\begin{gathered}
\frac{\partial \bar{U}}{\partial \bar{X}}+\frac{\partial \bar{V}}{\partial \bar{Y}}=0 \\
\rho\left(\frac{\partial \bar{U}}{\partial \bar{t}}+\bar{U} \frac{\partial \bar{U}}{\partial \bar{X}}+\bar{V} \frac{\partial \bar{U}}{\partial \bar{Y}}\right)=-\frac{\partial \bar{P}}{\partial \bar{X}}+\frac{\partial}{\partial \bar{X}} \bar{S}_{\overline{X X}}+\frac{\partial}{\partial \bar{Y}} \bar{S}_{\overline{X Y}}+\rho_{e} E_{x}+\rho g \sin \alpha \\
\rho\left(\frac{\partial \bar{U}}{\partial \bar{t}}+\bar{U} \frac{\partial \bar{V}}{\partial \bar{X}}+\bar{V} \frac{\partial \bar{V}}{\partial \bar{Y}}\right)=-\frac{\partial \bar{P}}{\partial \bar{Y}}+\frac{\partial}{\partial \bar{X}} \bar{S}_{\bar{Y} \bar{X}}+\frac{\partial}{\partial \bar{Y}} \bar{S}_{\overline{Y Y}}-\rho g \cos \alpha, \\
\rho c_{p}\left(\frac{\partial \bar{T}}{\partial \bar{t}}+\bar{U} \frac{\partial \bar{T}}{\partial \bar{X}}+\bar{V} \frac{\partial \bar{T}}{\partial \bar{Y}}\right)=\frac{\partial}{\partial \bar{Y}}\left(k(\bar{T}) \frac{\partial \bar{T}}{\partial \bar{Y}}\right)+\frac{\partial}{\partial \bar{X}}\left(k(\bar{T}) \frac{\partial \bar{T}}{\partial \bar{X}}\right)+\bar{S}_{\overline{X X}} \frac{\partial \bar{U}}{\partial \bar{X}}+\bar{S}_{\overline{Y Y}} \frac{\partial \bar{V}}{\partial \bar{Y}}+\bar{S}_{\overline{X Y}}\left(\frac{\partial \bar{V}}{\partial \bar{X}}+\frac{\partial \bar{U}}{\partial \bar{Y}}\right), \\
\left(\frac{\partial \bar{C}}{\partial \bar{t}}+\bar{U} \frac{\partial \bar{C}}{\partial \bar{X}}+\bar{V} \frac{\partial \bar{C}}{\partial \bar{Y}}\right)=D\left(\frac{\partial^{2} \bar{C}}{\partial \overline{X^{2}}}+\frac{\partial^{2} \bar{C}}{\partial \overline{Y^{2}}}\right)+\frac{D K_{T}}{T_{m}}\left(\frac{\partial^{2} \bar{T}}{\partial \overline{X^{2}}}+\frac{\partial^{2} \bar{T}}{\partial \overline{Y^{2}}}\right) .
\end{gathered}
$$

The constitutive equation for Jeffrey liquid is given through [3]:

$$
\bar{\tau}=-\bar{p} I+\bar{S}, \bar{S}=\frac{\mu(y)}{1+\lambda_{1}}\left(\overline{\dot{\gamma}}+\lambda_{2} \overline{\dot{\gamma}}\right),
$$

where $\bar{\tau}$ denotes the Cauchy stress tensor, $I$ is the identity tensor, $\lambda_{2}$ denotes the retardation time, $\bar{S}$ is the extra stress tensor, $\lambda_{1}$ presents the ratio of relaxation to retardation times, $\bar{p}$ is the pressure, $\dot{\gamma}$ represents the shear rate, and dots on the quantities specify differentiation with respect to time.

The Poisson Equation in the microchannel is [41]

$$
\nabla^{2} \bar{\phi}=-\frac{\rho_{e}}{\xi}
$$


where $\rho_{e}$ denotes the total charge density, $\xi$ is the dielectric permittivity, and $\bar{\phi}$ is the electric potential.

The net charge density $\rho_{e}$ follows the Boltzmann variation, given as [42]

$$
\rho_{e}=-z_{v} e\left(\bar{n}^{-}-\bar{n}^{+}\right) .
$$

The anions $\left(\bar{n}^{-}\right)$and cations $\left(\bar{n}^{+}\right)$are defined by $\rho_{e}$ of the Boltzmann equation:

$$
\bar{n}=\overline{n_{0}} e^{\left(\frac{e z V_{0}}{T_{a v} \bar{S}_{B}} \bar{\phi}\right)},
$$

where $n_{0}$ represents bulk concentration, $z_{v}$ the charge balance, $T_{a v}$ the average temperature, $e$ the electronic charge, and $K_{B}$ the Boltzmann constant.

Using Debye-Hückel linearization approximation, Equation (8) turns into

$$
\frac{d^{2} \phi}{d y^{2}}=m_{e}^{2} \phi,
$$

where $m_{e}$ represents the electroosmotic term. The analytical solution of above Equation (11) subject to boundary conditions $\frac{\partial \phi}{\partial y}=0$, at $\phi=1$ and $y=0$, at $y=h(x)$ is attained as [42]

$$
\phi(y)=\frac{\cosh \left(m_{e} y\right)}{\cosh \left(m_{e} h\right)}
$$

The conversion from laboratory frame $(\bar{X}, \bar{Y})$ to wave frame of references $(\bar{x}, \bar{y})$ is as follows:

$$
\begin{gathered}
\bar{y}=\bar{Y}, \bar{x}=\bar{X}-c \bar{t}, \bar{p}(\bar{x}, \bar{y})=\bar{P}(\bar{X}, \bar{Y}, \bar{t}), \bar{v}(\bar{x}, \bar{y})=\bar{V}(\bar{X}, \bar{Y}, \bar{t}), \bar{u}(\bar{x}, \bar{y}) \\
=\bar{U}(\bar{X}, \bar{Y}, \bar{t})-c, \bar{T}(\bar{x}, \bar{y})=\bar{T}(\bar{X}, \bar{Y}, \bar{t}) .
\end{gathered}
$$

The above conversions are utilized in Equations (2)-(6) and then introduce the dimensionless variables:

$$
\begin{gathered}
x=\frac{2 \pi \bar{x}}{\lambda}, y=\frac{\bar{y}}{a_{0}}, t=\frac{2 \pi c \bar{t}}{\lambda}, u=\frac{\bar{u}}{c}, v=\frac{\bar{v}}{c}, p=\frac{2 \pi a_{0}^{2} \bar{p}}{\lambda \mu_{0} c}, \alpha_{1}=\frac{2 \pi a_{0}}{\lambda}, m_{e}=\frac{a_{0}}{\lambda_{D}}, \\
n=\frac{\bar{n}}{n_{0}}, \epsilon=\frac{b}{a_{0}}, \theta=\frac{\bar{T}-T_{0}}{T_{0}}, \sigma=\frac{\bar{C}-C_{0}}{C_{0}}, \lambda_{D}=\frac{1}{e Z_{v}} \sqrt{\frac{T_{0} \zeta K_{B}}{2 n_{0}}}, \phi=\frac{e z z_{v} \bar{\phi}}{T_{a v} K_{B}}, U_{h s}=-\frac{E_{x} \bar{\xi}}{c \mu_{0}}, \\
S=\frac{a \bar{S}}{c \mu_{0}}, \psi=\frac{\bar{\psi}}{c a_{0}}, u=\frac{\partial \psi}{\partial y}, v=-\alpha_{3} \frac{\partial \psi}{\partial x}, R_{e}=\frac{\rho c a_{0}}{\mu_{0}}, P_{r}=\frac{\mu_{0} c_{p}}{k(T)}, B r=E_{c} \times P_{r}, \\
S r=\frac{\rho T_{0} K_{T} D_{m}}{\mu_{0} T_{m} C_{0}}, S c=\frac{\mu_{0}}{\rho D_{m}}, E_{c}=\frac{c^{2}}{c_{p} T_{0}}, \mu_{0}=\frac{\overline{\mu_{0}}}{\mu}, F=\frac{\theta c}{g a_{0}^{2}}, m_{1}=\frac{\lambda K}{a_{0}}, \\
h=\frac{\bar{h}}{a_{0}}=1+\frac{\lambda K x}{a_{0}}+\varepsilon \sin \left[\frac{2 \pi}{\lambda}(x-t)\right], E_{1}=\frac{-\tau a_{0}^{3}}{\lambda \mu_{0}^{3} c}, E_{2}=\frac{m_{1} c a_{0}^{3}}{\lambda^{3} \mu_{0}}, E_{3}=\frac{m_{2} a_{0}^{3}}{\lambda^{3} \mu_{0}}, \\
E_{4}=\frac{m_{3} a_{0}^{3}}{\lambda^{3} \mu_{0} c}, E_{5}=\frac{H a_{0}^{3}}{\lambda \mu_{0} c} .
\end{gathered}
$$

Here, $\lambda_{D}$ is the Debye length, $S c$ the Schmidt number, $y$ is the dimensionless transverse coordinate, $U_{h s}$ is the Helmholtz-Smoluchowski velocity, $m_{e}$ is the electroosmotic term, $p$ is dimensionless pressure, $\Omega$ is the concentration, $\alpha_{3}$ is the peristaltic wave number, $\theta$ is the temperature, $P_{r}$ is the Prandtl number, $\psi$ is a dimensionless stream function, $S$ is the dimensionless shear stress, $R_{e}$ is the Reynolds number, $B r$ is the Brinkman number, $\epsilon$ is the amplitude ratio, $S r$ is the dimensionless Soret number, $x$ is the dimensionless axial coordinate, and $E_{c}$ is the Eckert number.

The governing equation of movement of the flexible wall may be articulated as

$$
R(h)=p-p_{0},
$$


where $R$ is an operator that is utilized to represent the movement of stretched membrane through viscous damping forces, such that

$$
R=-\tau \frac{\partial^{2}}{\partial x^{2}}+n_{1} \frac{\partial^{2}}{\partial t^{2}}+n_{2} \frac{\partial}{\partial t}+n_{3} \frac{\partial^{4}}{\partial x^{4}}+H
$$

Continuity of stress at $y=h$ and utilizing $x$-momentum equation yield

$$
\frac{\partial p}{\partial x}=E_{1} \frac{\partial^{3} h}{\partial x^{3}}+E_{2} \frac{\partial^{3} h}{\partial x \partial t^{2}}+E_{3} \frac{\partial^{2} h}{\partial x \partial t}+E_{4} \frac{\partial^{5} h}{\partial x^{5}}+E_{5} \frac{\partial h}{\partial x} .
$$

where $\tau$ represents the elastic tension in the membrane, $n_{1}$ denotes the mass per unit area, $n_{2}$ is the coefficient of viscous damping forces, $h$ represents the dimensional slip term, and $p_{0}$ denotes the pressure over the outside area of the wall due to the tension in the muscles. We supposed $p_{0}=0$.

Equation (2) is identically satisfied and, from Equations (3)-(6), subject to longwavelength assumption and ignoring superior powers of $\alpha_{3}$, we acquire

$$
\begin{gathered}
\frac{\partial p}{\partial x}=\frac{\partial}{\partial y}\left[\left(\frac{1-\alpha_{1} y}{1+\lambda_{1}}\right) \frac{\partial^{2} \psi}{\partial y^{2}}\right]+m_{e}^{2} U_{h s} \phi+\frac{\sin \alpha}{F} \\
\frac{\partial p}{\partial y}=0 \\
\frac{\partial}{\partial y}\left(k(\theta) \frac{\partial \theta}{\partial y}\right)+B r\left[\left(\frac{1-\alpha_{1} y}{1+\lambda_{1}}\right) \frac{\partial^{2} \psi}{\partial y^{2}}\right] \frac{\partial^{2} \psi}{\partial y^{2}}=0 \\
\frac{\partial^{2} \Omega}{\partial y^{2}}+S c \times S r\left(\frac{\partial^{2} \theta}{\partial y^{2}}\right)=0
\end{gathered}
$$

The non-dimensional boundary conditions are

$$
\begin{gathered}
\frac{\partial^{2} \psi}{\partial y^{2}}=0, \psi=0, \frac{\partial \theta}{\partial y}=0, \frac{\partial \Omega}{\partial y}=0, \text { at } y=0 \\
\frac{\partial \psi}{\partial y}=-1, \Omega=0, \theta=0 a t y=h(x)=1+\mathrm{m}_{1} \mathrm{x}+\epsilon \sin \left(\frac{2 \pi}{\lambda}(x-c t)\right)
\end{gathered}
$$

The expression for variable viscosity is

$$
\mu(y)=1-\alpha_{1} y \text { for } \alpha_{1} \ll 1
$$

The thermal conductivity term is

$$
k(\theta)=1+\alpha_{2} \theta \text { for } \alpha_{2} \ll 1,
$$

where $\alpha_{1}$ is the coefficient of viscosity and $\alpha_{2}$ is the coefficient of thermal conductivity.

\section{Methodology}

The transformed governing equation and boundary conditions need to be solved using suitable analytical or semi-analytical methods to obtain the solution for velocity, temperature concentration, and streamlines. The semi-analytical technique, the perturbation method, is employed to solve the system of non-linear transformed equations.

\subsection{Perturbation Solution}

Equations (18)-(21) specify a governing differential system with boundary conditions (22) and (23) that are extremely nonlinear. It is impossible to find an exact solution to this system of equations. As a result, the system can be solved analytically using the 
perturbation method, which uses variable viscosity $\alpha_{1}$ and variable thermal conductivity $\alpha_{2}$ as perturbation terms. Thus, $\psi$ and $\theta$ can be expanded as

$$
\begin{gathered}
\psi=\psi_{0}+\alpha_{1} \psi_{1}+O\left(\alpha^{2}\right), \\
\theta=\theta_{0}+\alpha_{2} \theta_{1}+O\left(\beta^{2}\right) .
\end{gathered}
$$

Substituting Equations (26) and (27) in Equations (18) and (20) and collecting the same power terms and equating to zero yields the following systems.

\subsubsection{Zeroth Order System}

$$
\begin{gathered}
\frac{\partial^{3} \psi_{0}}{\partial y^{3}}-\left(1+\lambda_{1}\right)\left(P-m_{e}^{2} U_{h s} \phi\right), \\
\frac{\partial \theta_{0}}{\partial y}=-B r \int\left(\frac{1-\alpha_{1} y}{1+\lambda_{1}} \frac{\partial \psi^{2}}{\partial y^{2}}\right) \frac{\partial \psi^{2}}{\partial y^{2}} .
\end{gathered}
$$

Subject to the following boundary conditions

$$
\begin{gathered}
\psi_{0}=0, \frac{\partial^{2} \psi_{0}}{\partial y^{2}}=0, \frac{\partial \theta_{0}}{\partial y}=0 \text { at } y=0, \\
\frac{\partial \psi_{0}}{\partial y}=-1, \theta_{0}=0 \text { at } y=h .
\end{gathered}
$$

3.1.2. First Order System

$$
\begin{gathered}
\frac{\partial^{3} \psi_{1}}{\partial y^{3}}=y \frac{\partial^{3} \psi_{0}}{\partial y^{3}}+\frac{\partial^{2} \psi_{0}}{\partial y^{2}}, \\
\frac{\partial \theta_{1}}{\partial y}=-\theta_{0} \frac{\partial \theta_{0}}{\partial y} .
\end{gathered}
$$

Subject to the following boundary conditions

$$
\begin{gathered}
\psi_{1}=0, \frac{\partial^{2} \psi_{1}}{\partial y^{2}}=0, \frac{\partial \theta_{1}}{\partial y}=0 \text { at } y=0, \\
\frac{\partial \psi_{1}}{\partial y}=0, \theta_{0}=0
\end{gathered}
$$

The solution of zeroth and first order systems along with boundary conditions are obtained using the MATLAB code. The separate code has been written to acquire the solutions for streamline, velocity, and temperature. Further, the solution for Equation (21) is acquired by twice integrating the temperature term through the aid of boundary conditions (22) and (23).

\section{Results and Discussion}

The present investigations emphasize the impact of electroosmotic velocity $\left(U_{h s}\right)$, the electroosmotic parameter $\left(m_{e}\right)$, the Jeffrey parameter $\left(\lambda_{1}\right)$, variable viscosity $\left(\alpha_{1}\right)$, variable thermal conductivity $\left(\alpha_{2}\right)$, angle of inclination $(\alpha)$, the non-uniform parameter $\left(m_{1}\right)$, the wall tension parameter $\left(E_{1}\right)$, the mass characterization parameter $\left(E_{2}\right)$, the wall damping term $\left(E_{3}\right)$, the wall rigidity term $\left(E_{4}\right)$, the elastic term of the wall $\left(E_{5}\right)$, the Brinkmann number $(B r)$, the Schmidt number $(S c)$, and the Soret number $(S r)$ on velocity $(u)$, temperature $(\theta)$, concentration $(\phi)$, and streamlines $(\psi)$. The outcomes of these parameters are shown through Figures 2-13. 


\subsection{Velocity Profiles}

Figure 2 depicts the effect of relevant terms on velocity. The velocity profiles have a parabolic shape due to an optimum velocity in the conduit's center. Figure 2a shows that as $U_{h s}$, or the optimal electroosmotic velocity (or Helmholtz-Smoluchowski velocity), increases from -1 to 6 , the axial circulation has substantial momentum. For larger $U_{h s}$, a subsequent boost in an axial electric field causes a significant deceleration. The circulation is supported and obstructed by an essential electrical field strength. The more critical values of $m_{e}$ in Figure $2 \mathrm{~b}$ enhance the velocity profiles. Furthermore, there is a slight variation in velocity profiles for higher values. The mutual of the Debye length is the Debye-Hückel specification. Because increased ion migration occurs as we move away from the indicted area, the decreasing Debye length, i.e., the rising Debye-Hückel term, is thought to raise electrical capacity. As a result, the Debye length is a vital style criterion in managing potential electrical variation, which significantly impacts the axial velocity field. Figure $2 \mathrm{c}$ has been drawn for multiple values of the Jeffrey parameter. The velocity profile improves as the Jeffrey criterion rises, as shown in this graph. It is worth noting that by taking $\lambda_{1}=0$, the outcome decreases to Newtonian liquid. Figure $2 \mathrm{~d}$ depicts the effect of changeable viscosity over velocity profiles. The velocity profile enhances for more significant values of variable viscosity because a boost in variable viscosity parameters decreases the fluid's viscosity and thus improves the fluid circulation. Figure 2e reveals an augment in velocity profiles for more significant values of inclination parameters. The increase in the inclination angle gives rise to a gravitational force, and thus the velocity of the fluid increases for the higher value of the inclination angle. The effect of the nonuniform term over the velocity profile is depicted in Figure $2 \mathrm{f}$. Here, a rise in the value of the non-uniform term enhances the flow region and thereby increases the velocity profile. The impact of the wall tension term, the mass characterizing parameter, the wall damping term, the wall rigidity parameter, and the elastic parameter of the wall on the velocity profile is sketched in Figure 2g. The velocity can be seen to be decreasing as we move from the center of the channel towards the walls for each of these elastic parameters. Moreover, As $E_{1}$ and $E_{2}$ increase, the velocity rises, whereas with higher values of $E_{3}, E_{4}$, and $E_{5}$, the fluid decelerates. Clinically, when blood walls are flexible or the mass per unit surface rises (as in blood capillaries), the exchange of oxygen, water, and other nutrients becomes simple. The damping tends to react oppositely.

(a)

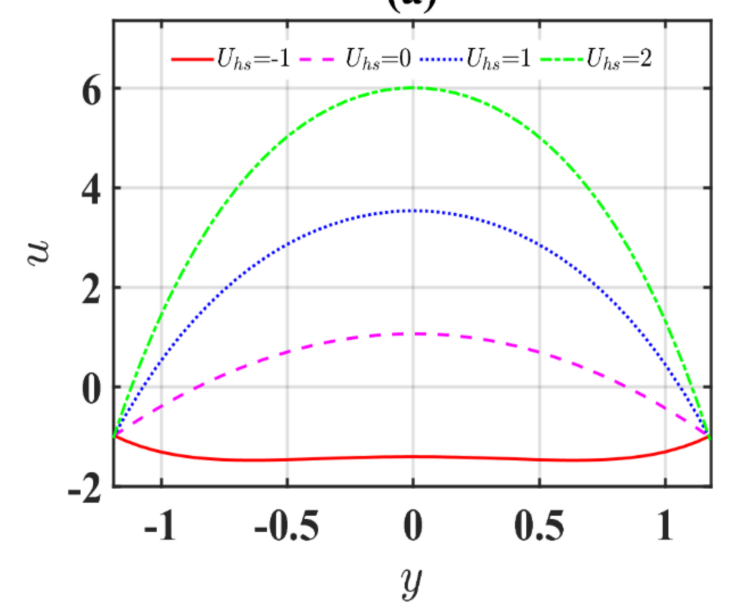

(b)

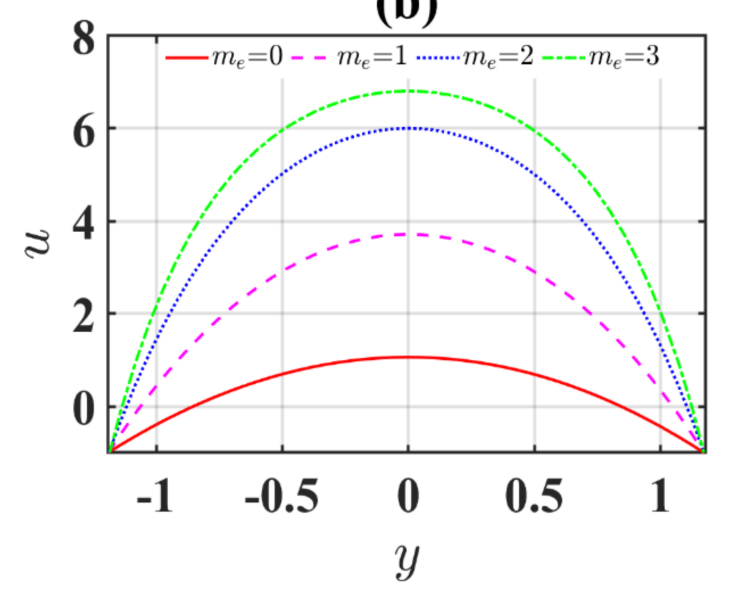

Figure 2. Cont. 
(c)

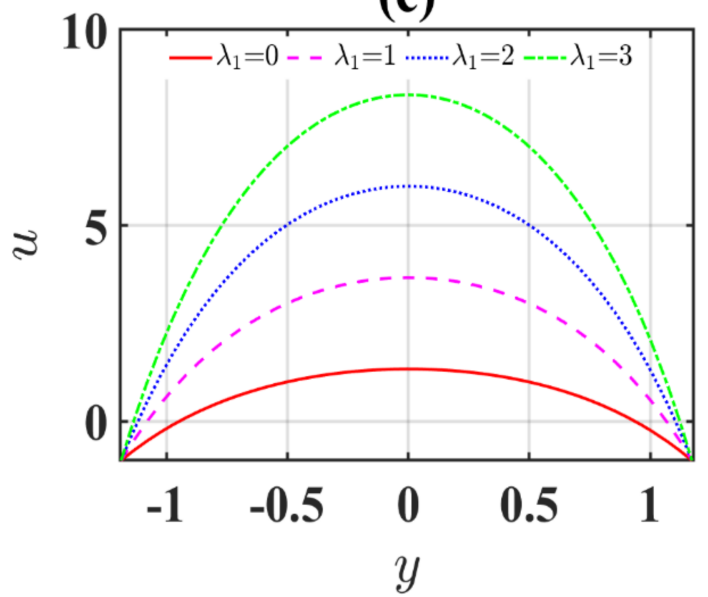

(e)

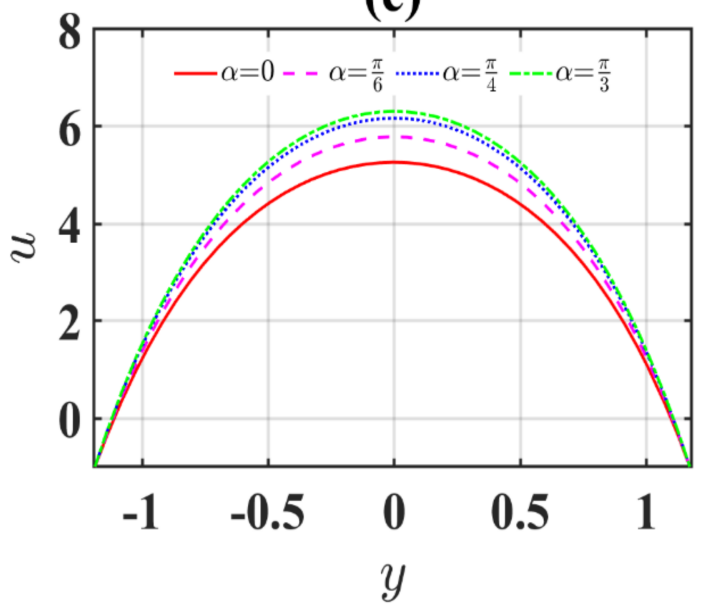

(d)

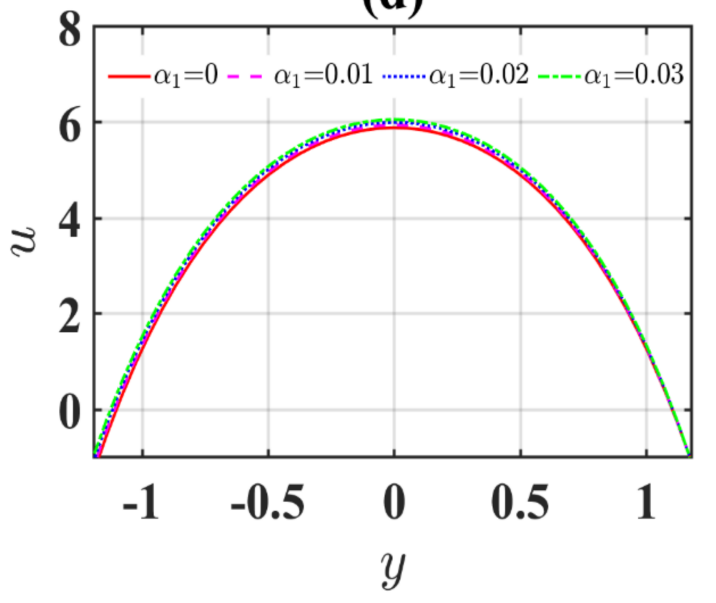

(f)

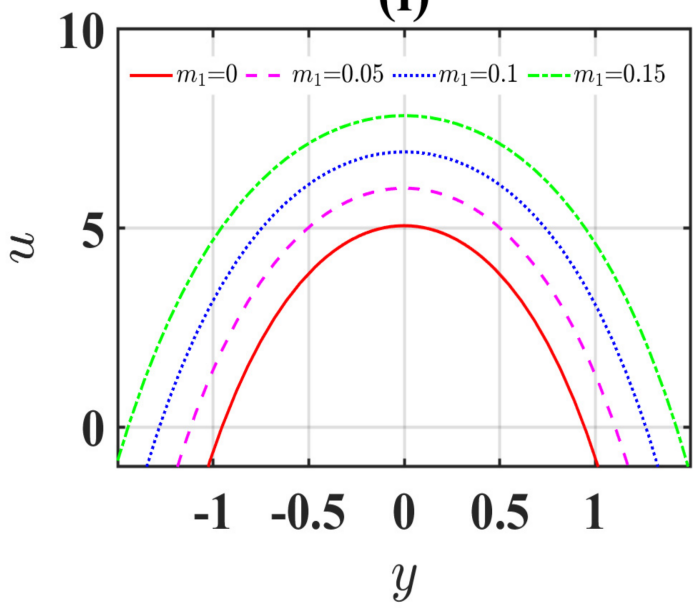

(g)

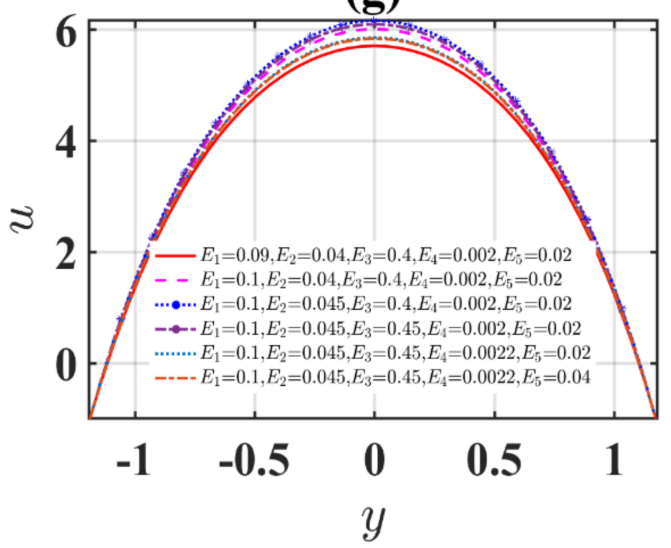

Figure 2. Velocity profiles for varying (a) $U_{h s},(\mathbf{b}) m_{e},(\mathbf{c}) \lambda_{1},(\mathbf{d}) \alpha_{1},(\mathbf{e}) \alpha,(\mathbf{f}) m_{1}$, and $(\mathbf{g}) E_{1}-E_{5}$.

\subsection{Temperature Profiles}

In this section, we examine the impact of various specifications on temperature profiles. The temperature distributions are parabolic through a maximum temperature level in the middle of the conduit. The ramifications of viscous dissipation, which raises the temperature in the center of the channel, may affect these habits. The viscosity of the liquid causes this phenomenon, which changes kinetic energy in the liquid into thermal energy inside it. Figure 3 a reveals that the temperature of the liquid rises through a boost in the 
maximum electroosmotic velocity. On the other hand, the temperature profile decreases for the increasing Debye-Hückel parameter (See Figure 3b). Figure $3 c$ is drawn to see the impact of the Jeffrey specification on the temperature profile. The figure reveals that temperature is a rising function of the Jeffrey specification. Figure $3 d$ is sketched to see the influence of variable thermal conductivity over the temperature profile. Thermal conductivity is the fluid's ability to protect or release heat to its settings. As a result, when the thermal conductivity of the liquid within the channel is higher than the wall temperature, the fluid's thermal evaluation increases. The impact of variable viscosity over temperature profile is illustrated in Figure 3e. Variable viscosity raises the temperature profile, and when variable viscosity amounts to absolutely zero, consistent viscosity can be derived. The reality is that, as the fluid's variable viscosity increases, the heat transfer prospective declines and raises the temperature profile. Figure $4 \mathrm{a}$ illustrates that the higher values of the inclination angle boost the temperature profiles. Figure $4 \mathrm{~b}$ shows that higher values of the Brinkmann number improve the temperature distribution. It is an argument that less heat conducts the viscous dissipation. The Brinkman number shows dissipation intensity. Given that the wall temperature is convectively regulated, heat transfers are considered because of the impacts of heat dissipation. A similar trend is noticed to that of Brinkmann number for an increase in the non-uniform parameter. (See Figure 4c). The effects of the elastic parameters $E_{1}, E_{2}, E_{3}, E_{4}$, and $E_{5}$ are sketched in Figure $4 \mathrm{~d}$. From the figure, it has been determined that the temperature profiles increase for larger values $E_{1}$ and $E_{2}$ in the non-uniform channel, whereas the opposite behaviour is noticed for $E_{3}, E_{4}$, and $E_{5}$

(a)

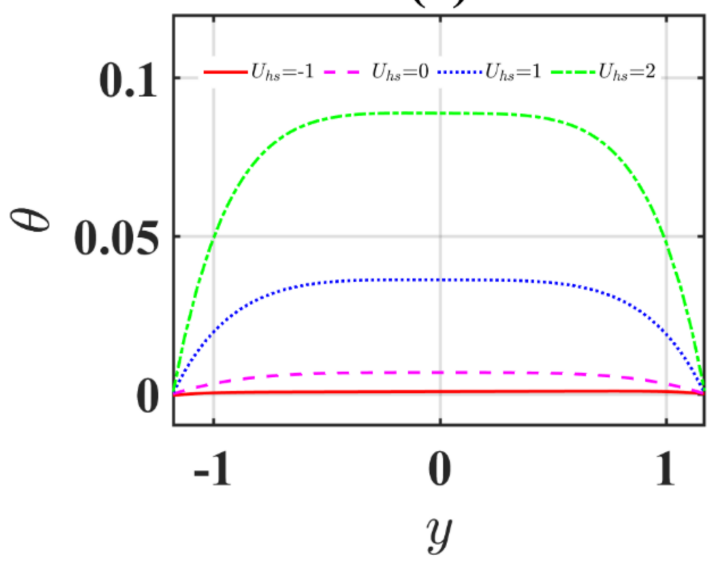

(c)

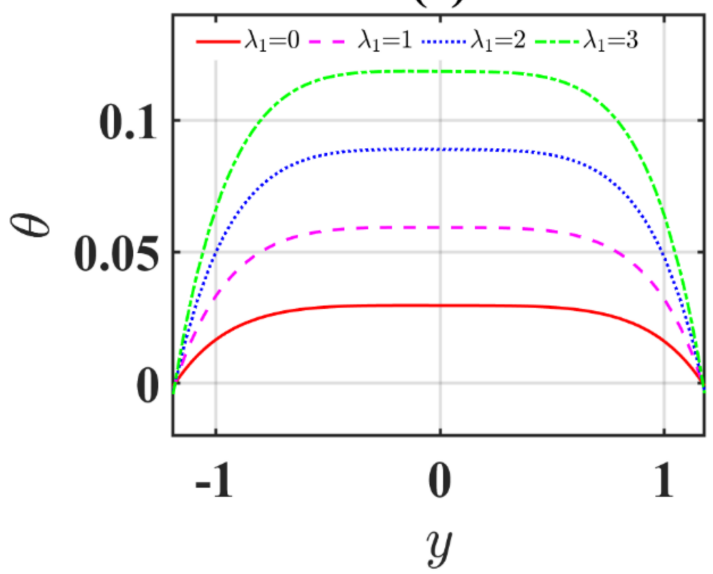

(b)

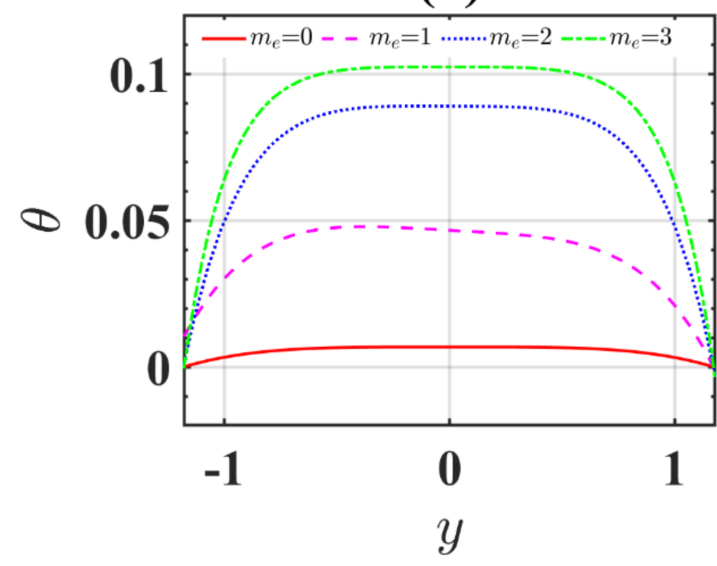

(d)

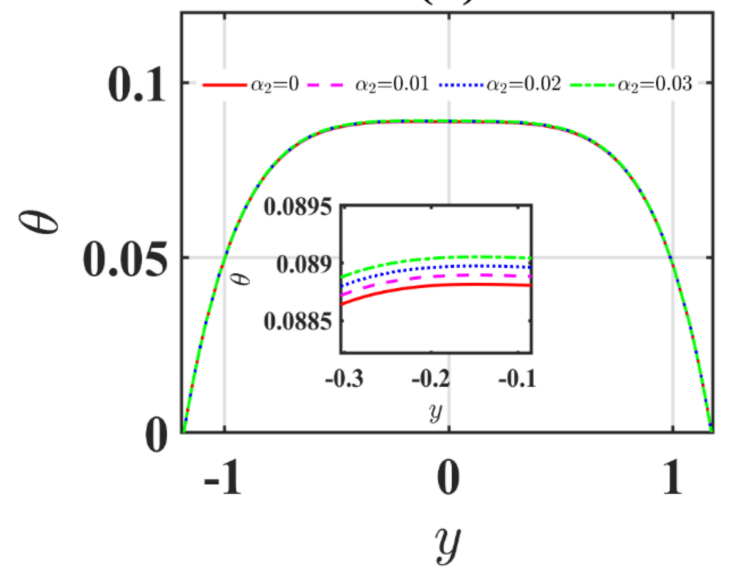

Figure 3. Cont. 


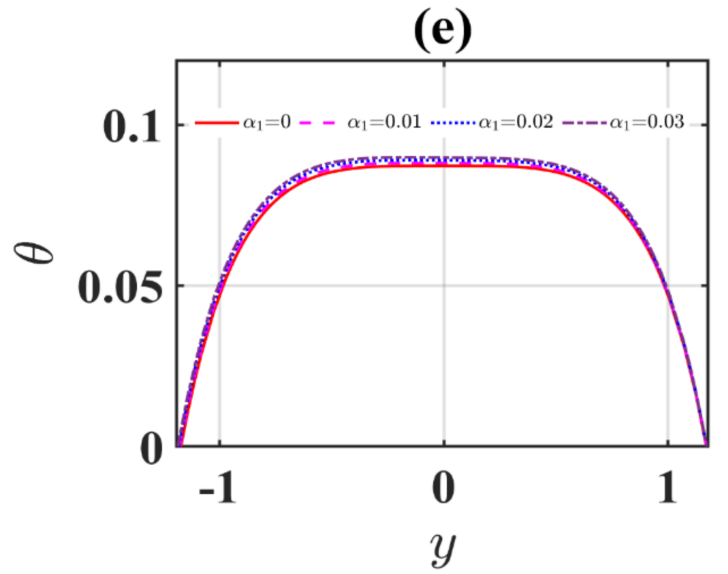

Figure 3. Temperature profiles for varying (a) $U_{h s}$, (b) $m_{e}$, (c) $\lambda_{1}$, (d) $\alpha_{2}$, and (e) $\alpha_{1}$.

(a)

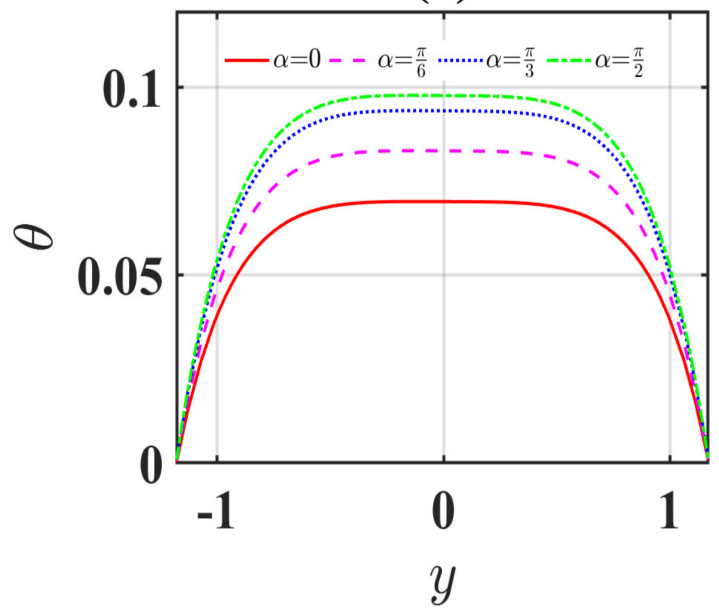

(c)

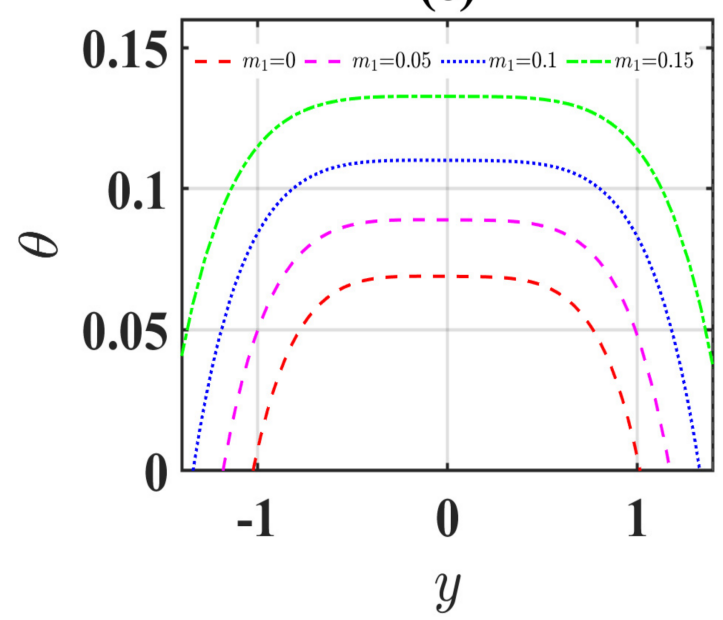

(b)

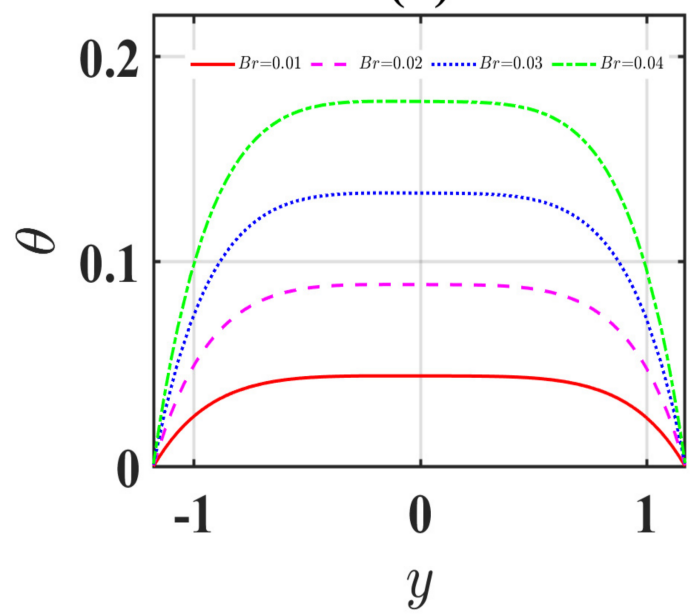

(d)

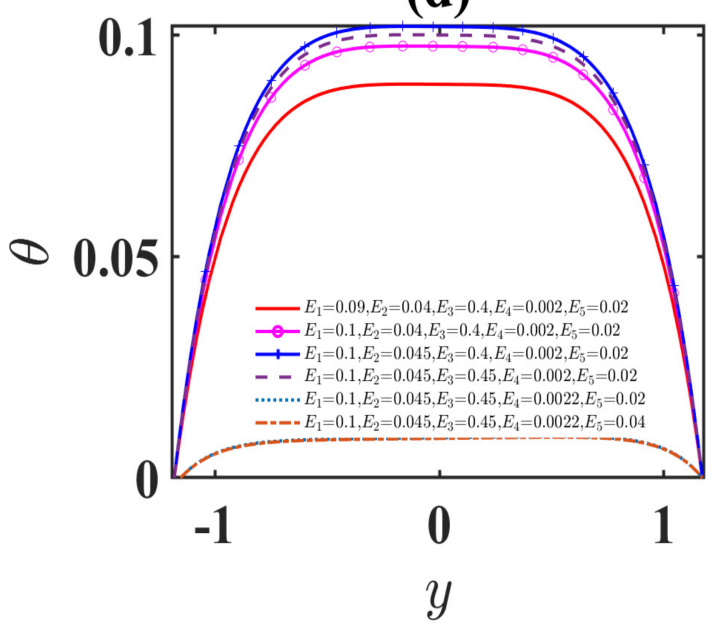

Figure 4. Temperature profiles for varying (a) $\alpha$, (b) $B r$, (c) $m_{1}$, and (d) $E_{1}-E_{5}$.

\subsection{Concentration Profiles}

Figures 5 and 6 demonstrate the impact of relevant pertinent parameters on concentration profiles. Figure 5a-e shows the effect of electroosmotic velocity, the electroosmotic 
parameter, the Jeffrey parameter, changeable thermal conductivity, and variable viscosity on the concentration profiles. The concentration profile behaves opposite to temperature profiles in Figure 5a-e. This behavior is predicted physically because mass and heat are comprehended to be opposite in direct proportion. In addition, the profiles reveal that particle matter in the liquid is more at the periphery than in the central location of the conduit. From a biological point of view, this behavior assists in spreading essential nutrients to nearby cells and tissues in the blood and other fluxes. The effect of the inclination angle on the concentration is drawn in Figure 5f. It can be noticed from the figure that enhancing the angle of inclination boosts the concentration profiles. Figure $6 \mathrm{a}, \mathrm{b}$ is sketched to see the impact of the Schmidt and Soret numbers on the concentration profiles. From the figures, the concentration profiles notably decrease through an augmented value of the Schmidt and Soret numbers. The impact of the Brinkman number and the non-uniform term on the concentration profiles are illustrated in Figure $6 \mathrm{c}$, d. It can be noticed that the concentration profiles decrease through a rise in the value of the Brinkman number and the non-uniform parameter. Figure 6e represents the impact of the elastic parameters $E_{1}, E_{2}, E_{3}, E_{4}$, and $E_{5}$ on concentration profiles. It has been noted that the rise in the values of $E_{1}$ and $E_{2}$ enhances the concentration, whereas the opposite behavior is observed for an increase in the values of $E_{3}, E_{4}$, and $E_{5}$.
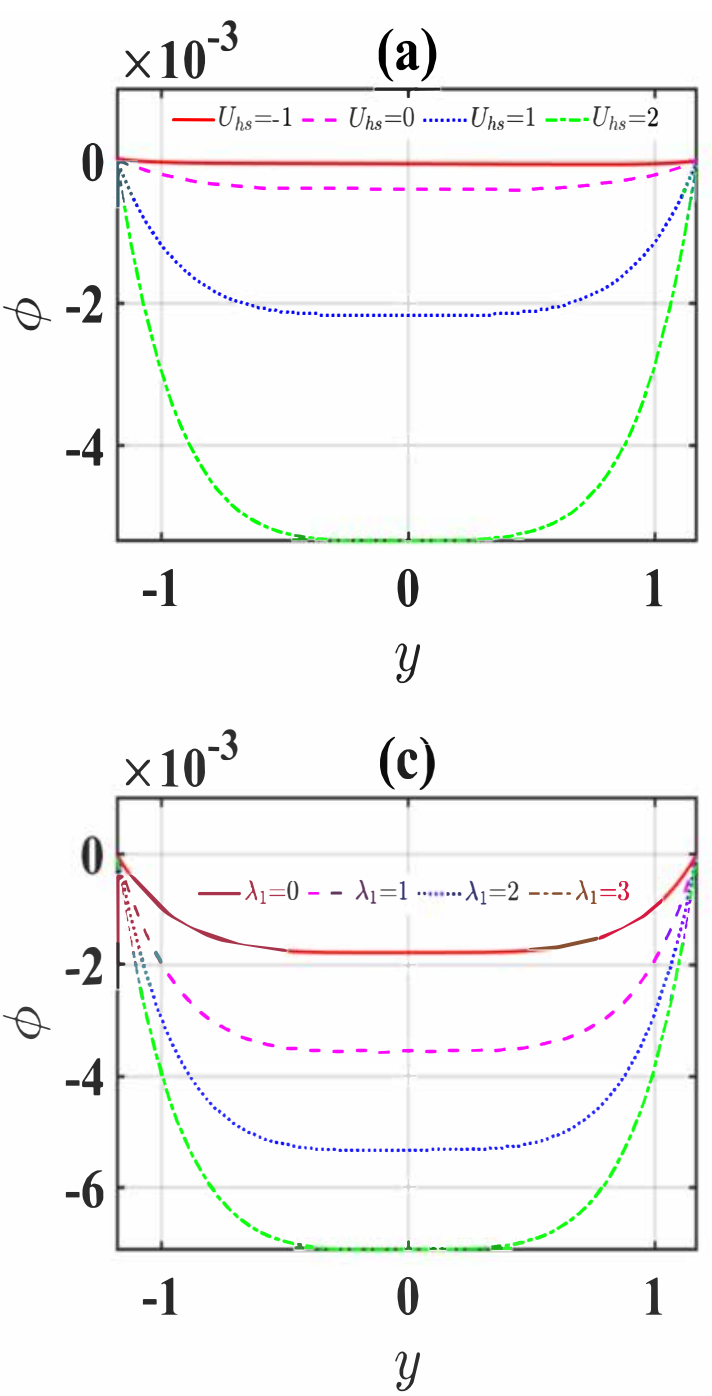
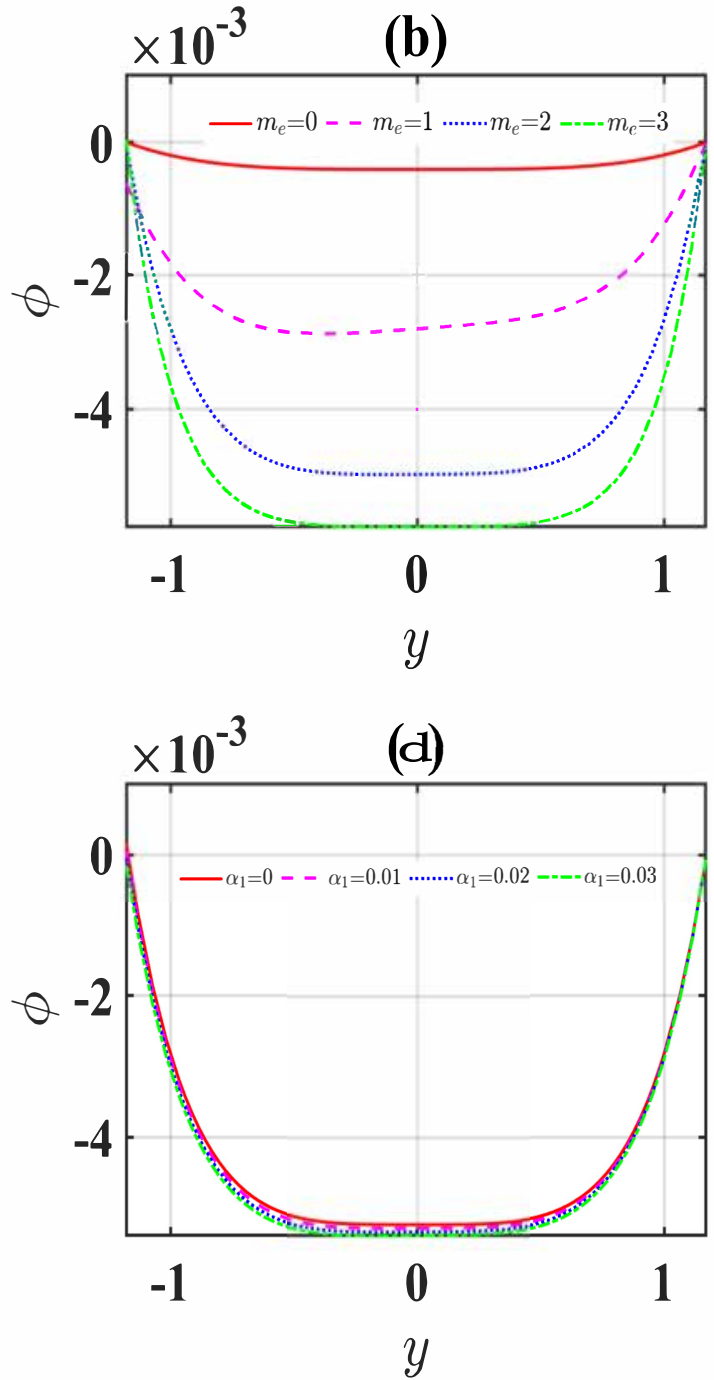

Figure 5. Cont. 

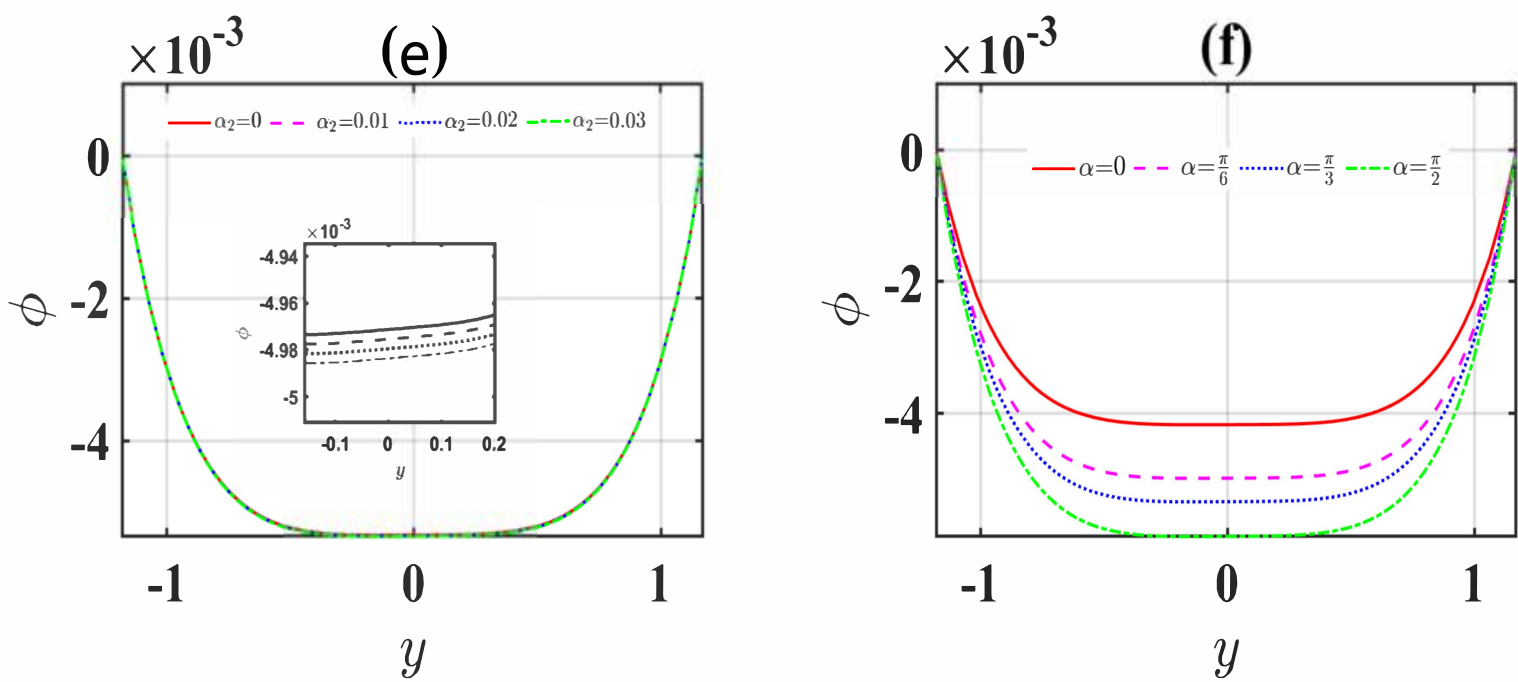

Figure 5. Concentration profiles for varying (a) $U_{h s^{\prime}},(\mathbf{b}) m_{e},(\mathbf{c}) \lambda_{1},(\mathbf{d}) \alpha_{2},(\mathbf{e}) \alpha_{1}$, and (f) $\alpha$.
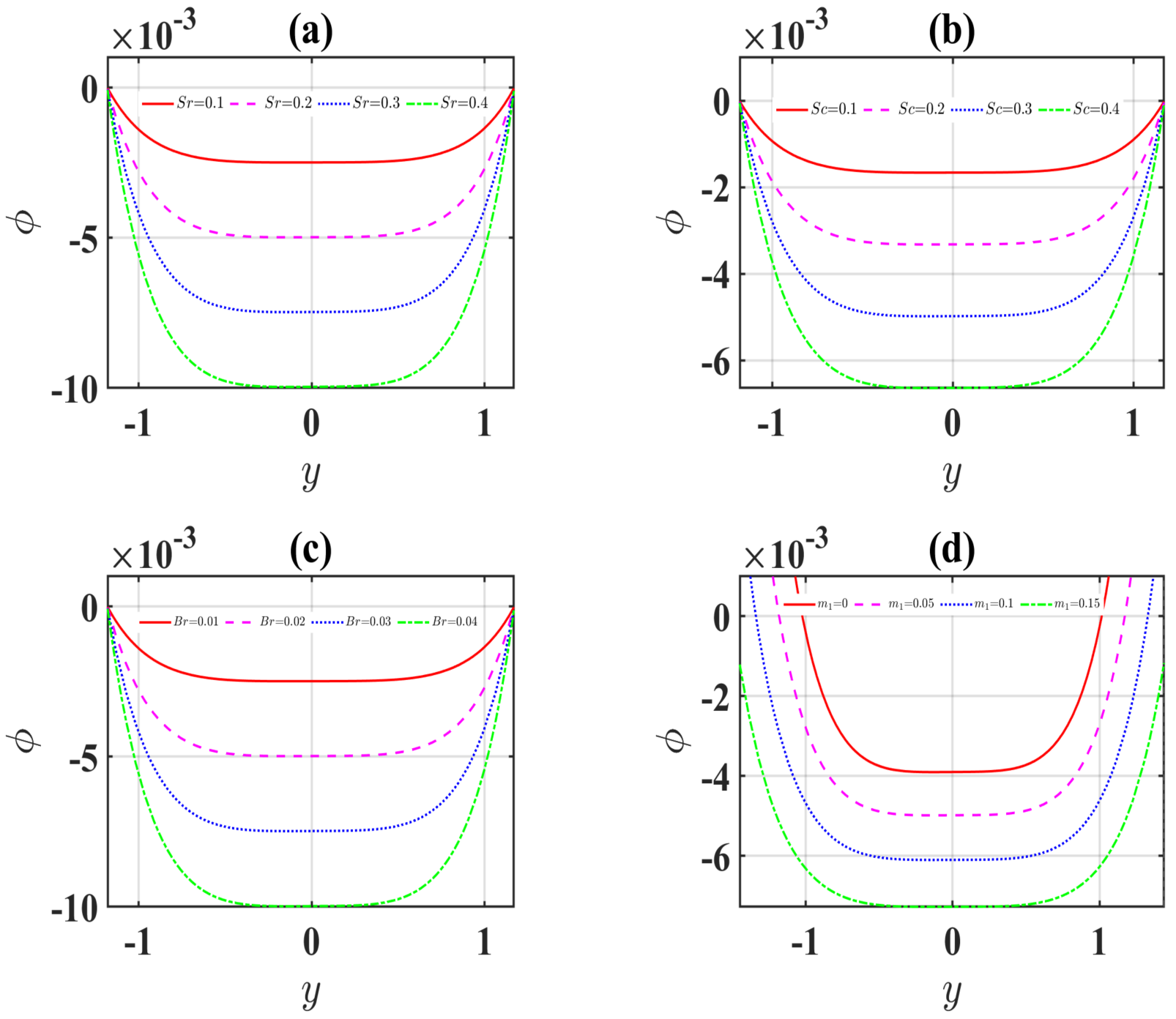

Figure 6. Cont. 


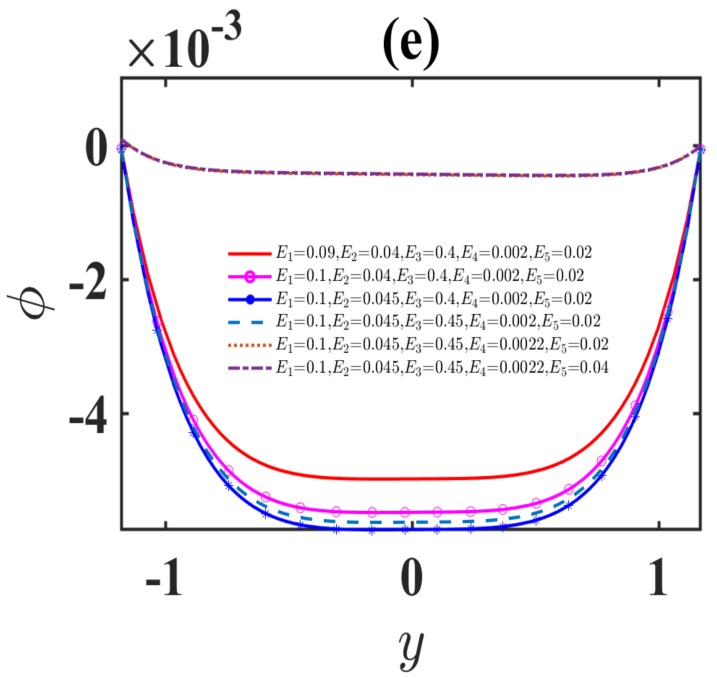

Figure 6. Concentration profiles for varying (a) $S r$, (b) $S c$, (c) $B r$, (d) $m_{1}$, and (e) $E_{1}-E_{5}$.

\subsection{Trapping Phenomenon}

Trapping is the most interesting and common phenomenon in the peristaltic transport of bio fluids. The behavior of the relevant parameters over the bolus is analyzed with the help of contours. Figure $7 \mathrm{a}-\mathrm{d}$ is drawn for the influence of electroosmotic velocity on the trapped bolus. From the figure, the formation of boluses increases drastically through the higher values of electroosmotic velocity. This is because powerful electroosmotic velocity means a dominant external electrical field; the variety of enclosed boluses considerably diminishes for large values of electroosmotic velocity. Figure 8 explains that the union of enclosed boluses rises through an enhancement in the electroosmotic term. It can be noticed that the larger the value of electroosmotic parameter, the stronger the enclosed bolus appears in EDL. Figure 9 is drawn for the effect of the Jeffery parameter on the trapped bolus. The figure reveals that the volume of the trapped bolus improves with a larger value of the Jeffery parameter. A similar trend has been observed for the rise in the significance of variable viscosity, angle of inclination, and the non-uniform parameter. (See Figures 10-12). Figure 13 illustrates the influence of the elastic parameter $E_{1}, E_{2}, E_{3}, E_{4}$ and $E_{5}$ on the trapped bolus. The volume of the trapped bolus decreases for larger values of $E_{5}$, and it increases for $E_{1}, E_{2}, E_{3}$, and $E_{4}$.

(a)

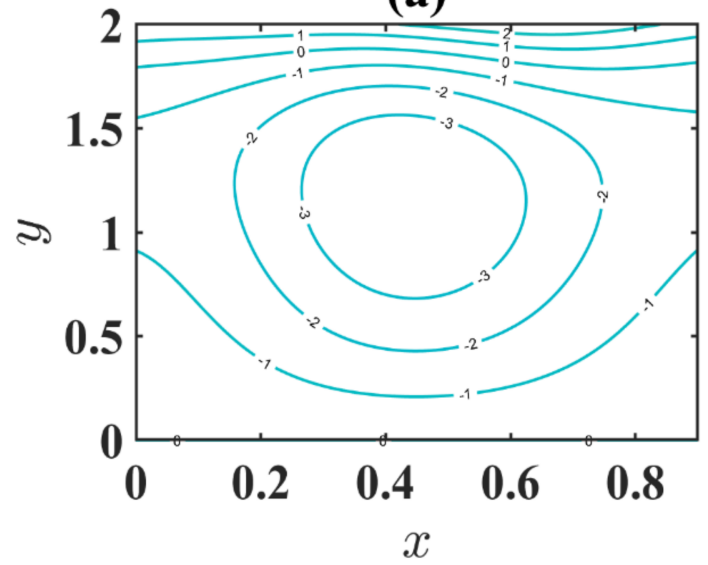

(b)

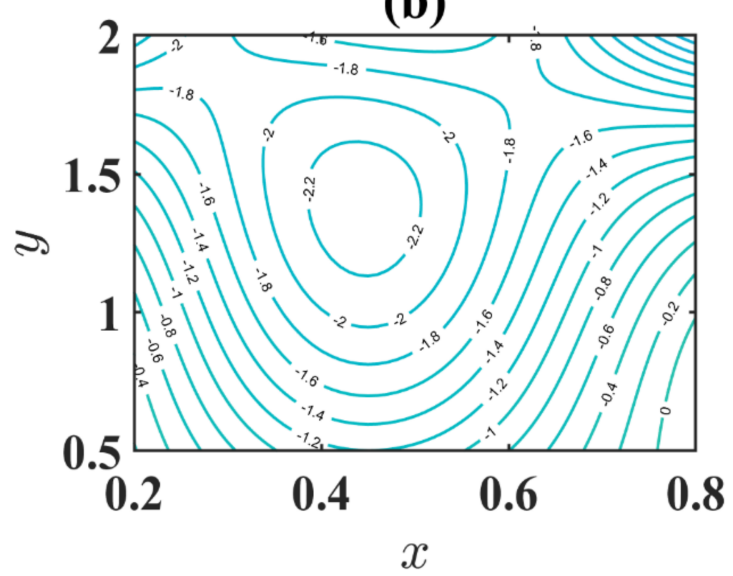

Figure 7. Cont. 

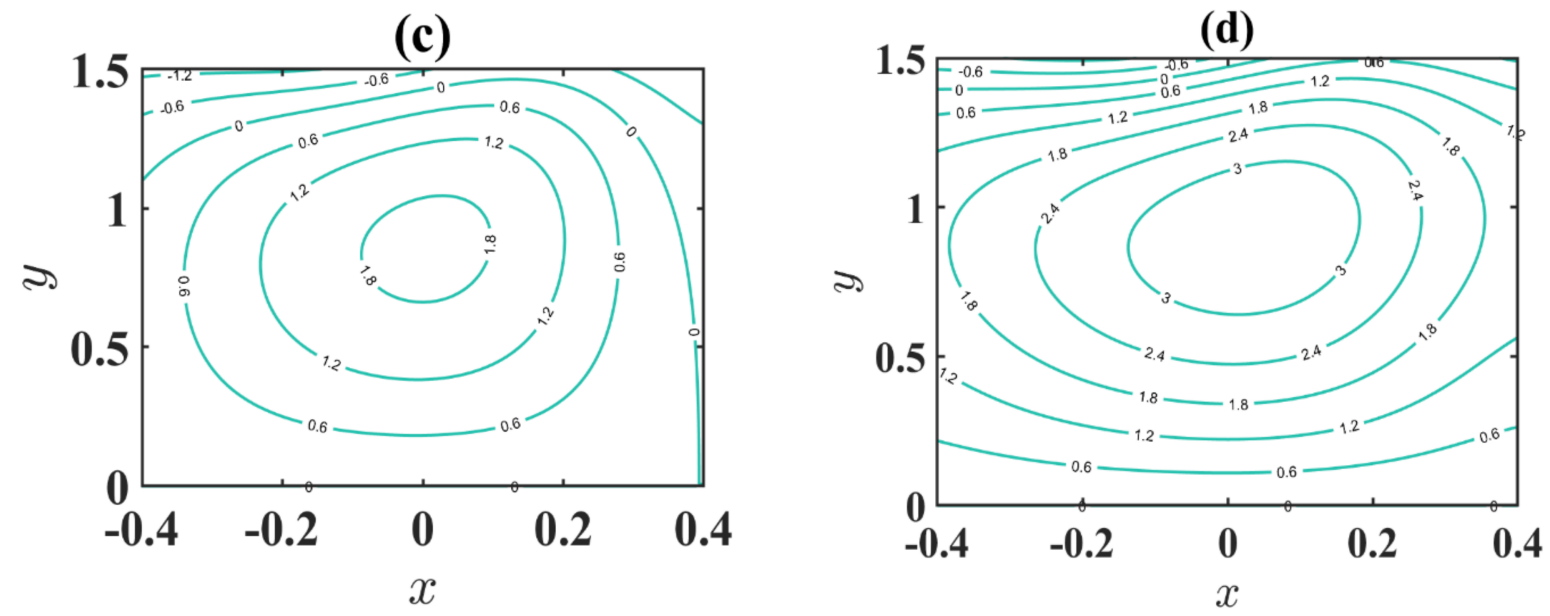

Figure 7. Streamlines for (a) $U_{h s}=-1$, (b) $U_{h s}=0$, (c) $U_{h s}=1$ and (d) $U_{h s}=2$.
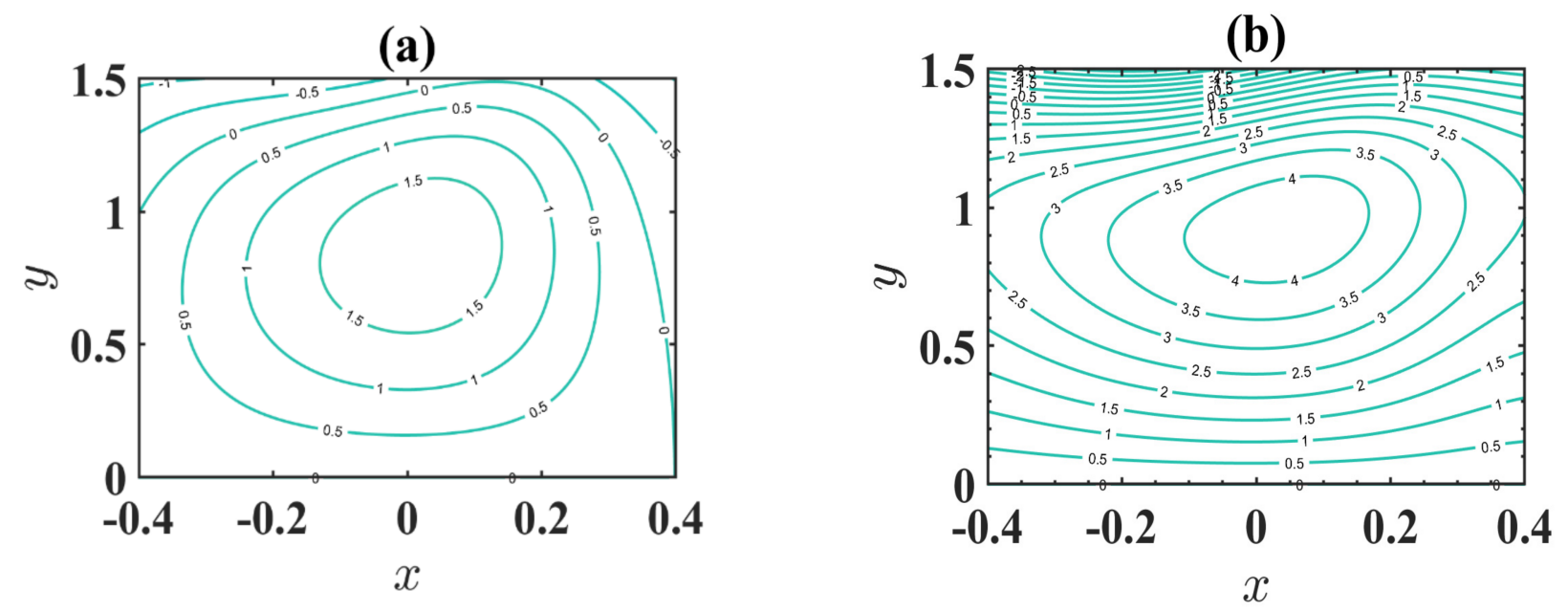

Figure 8. Streamlines for (a) $m_{e}=1$ and (b) $m_{e}=3$.
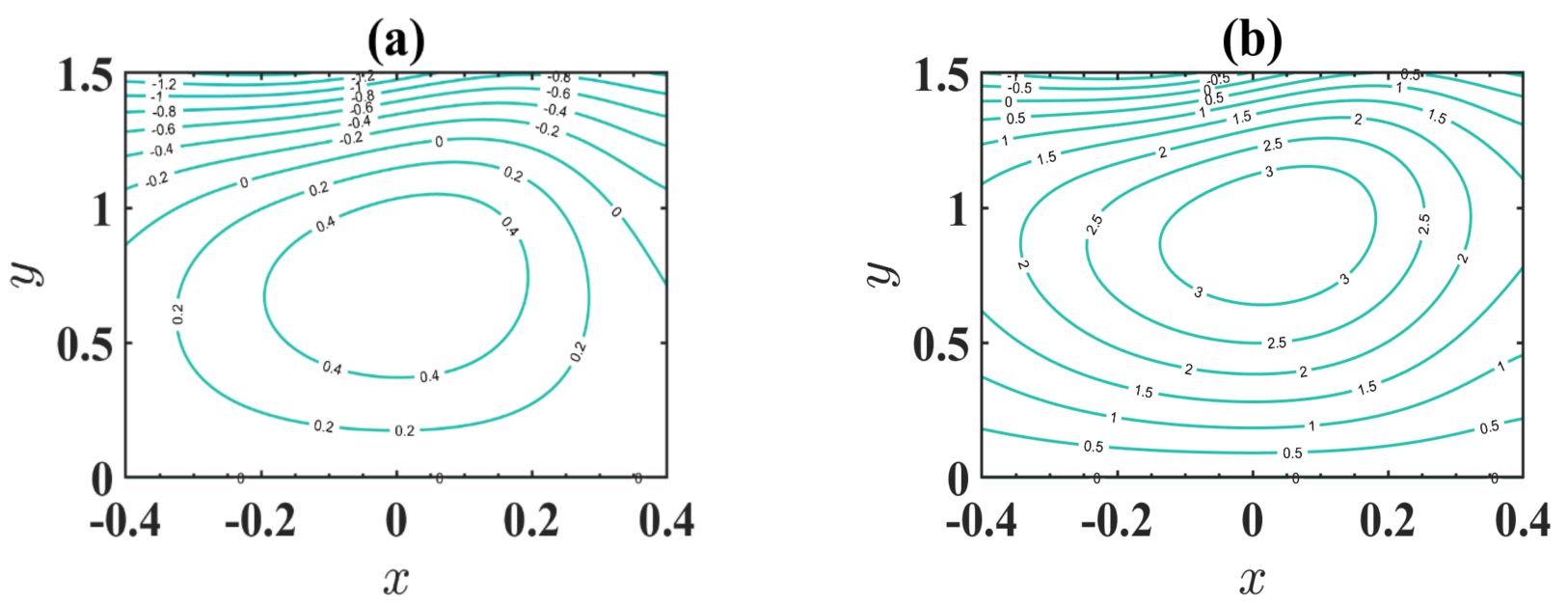

Figure 9. Streamline for varying (a) $\lambda_{1}=0$ and (b) $\lambda_{1}=2$. 
(a)

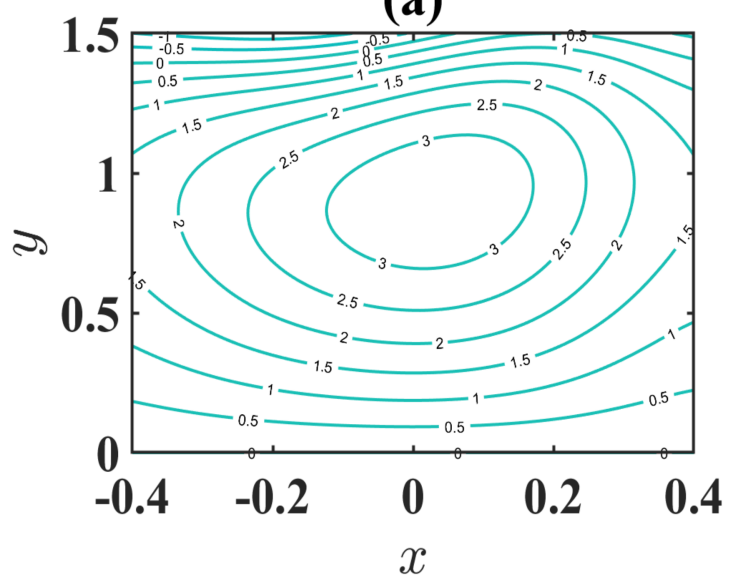

(b)

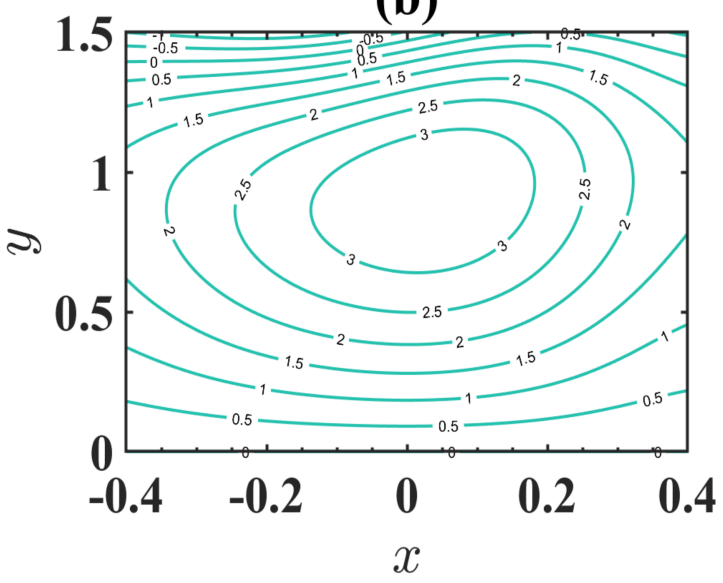

Figure 10. Streamline for varying (a) $\alpha_{1}=0$ and (b) $\alpha_{1}=0.02$.

(a)

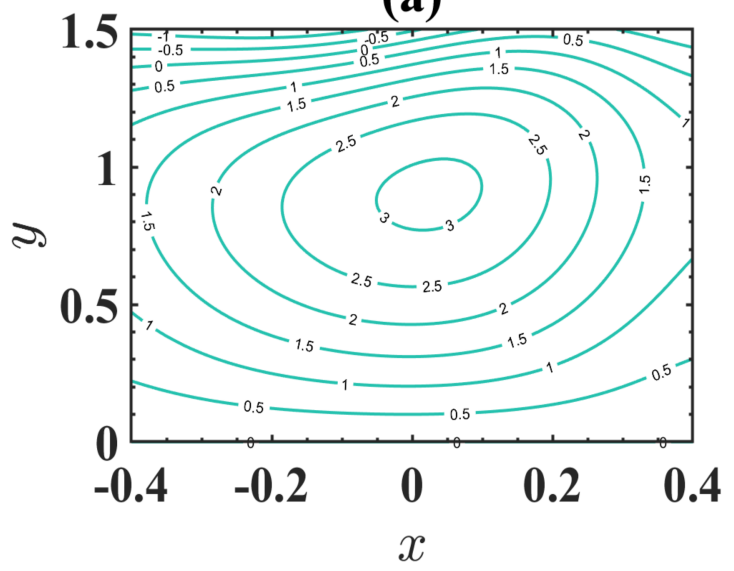

(b)

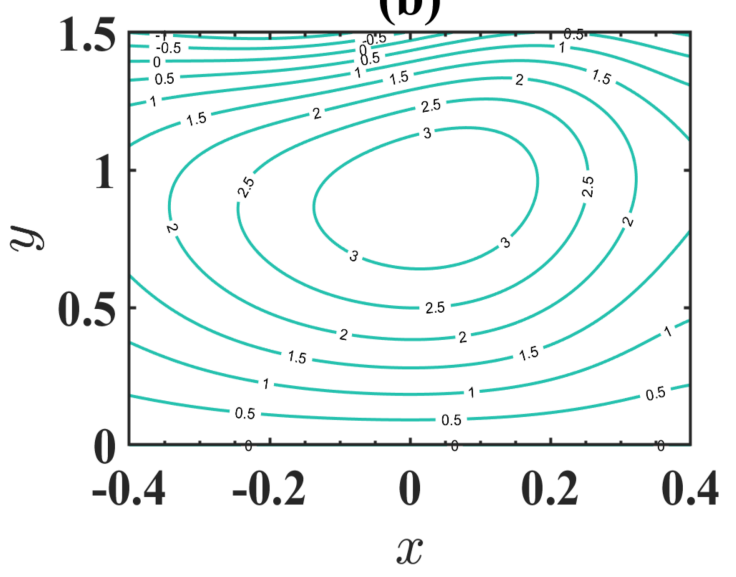

Figure 11. Streamline for varying (a) $\alpha=0$ and (b) $\alpha=\frac{\pi}{4}$.

(a)

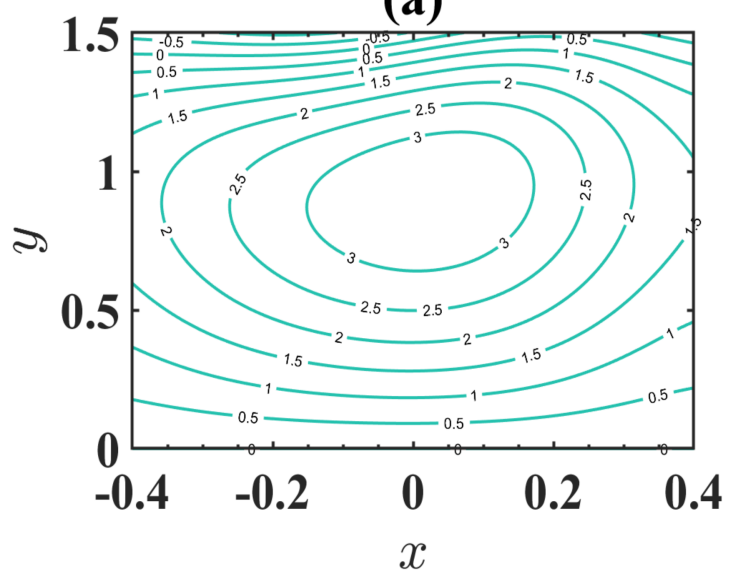

(b)

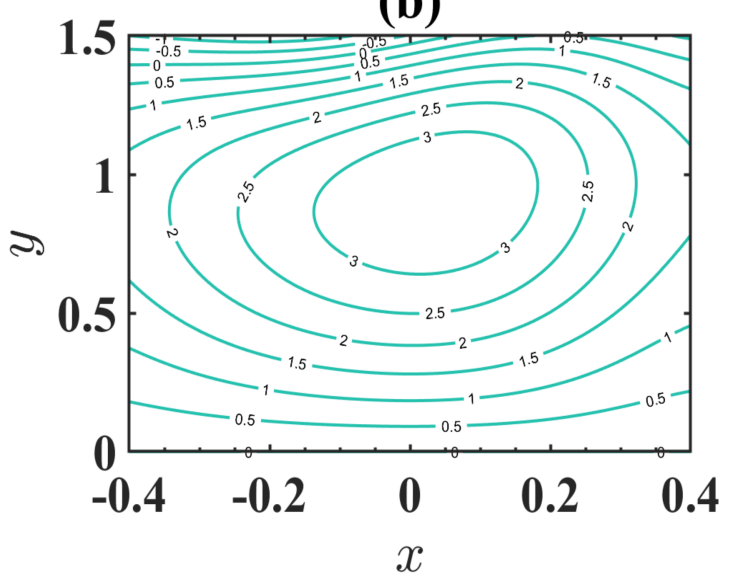

Figure 12. Streamlines for (a) $m_{1}=0$ and (b) $m_{1}=0.05$. 


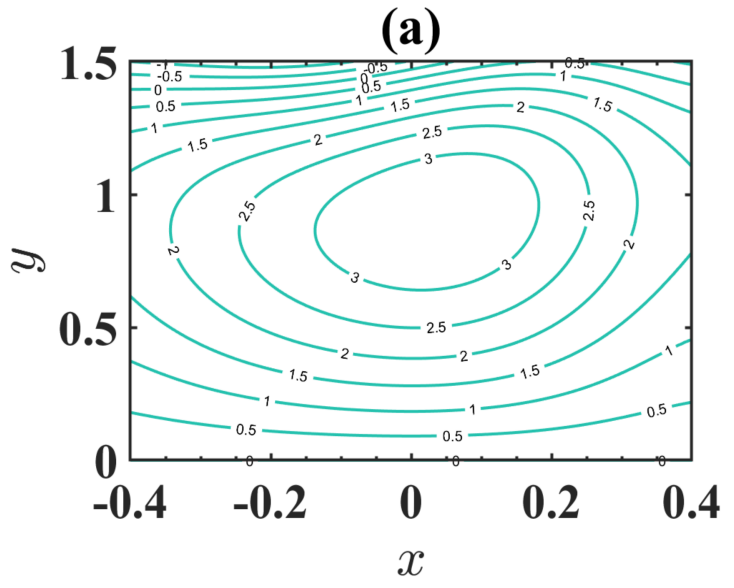

(c)

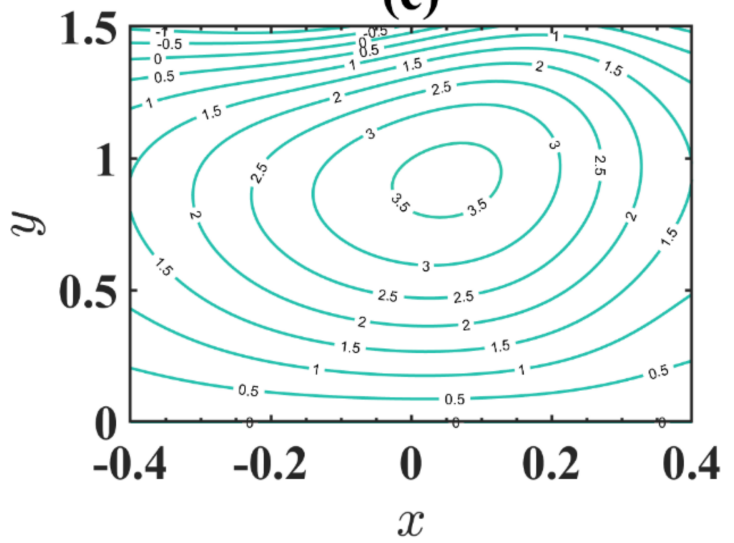

(e)

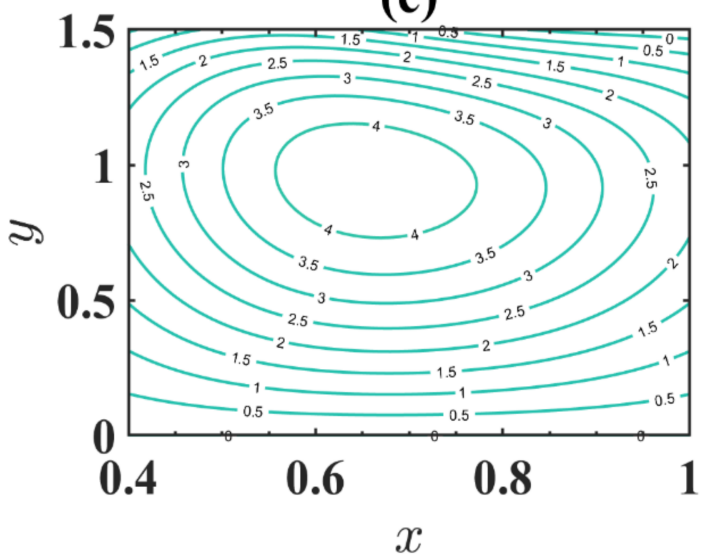

(b)

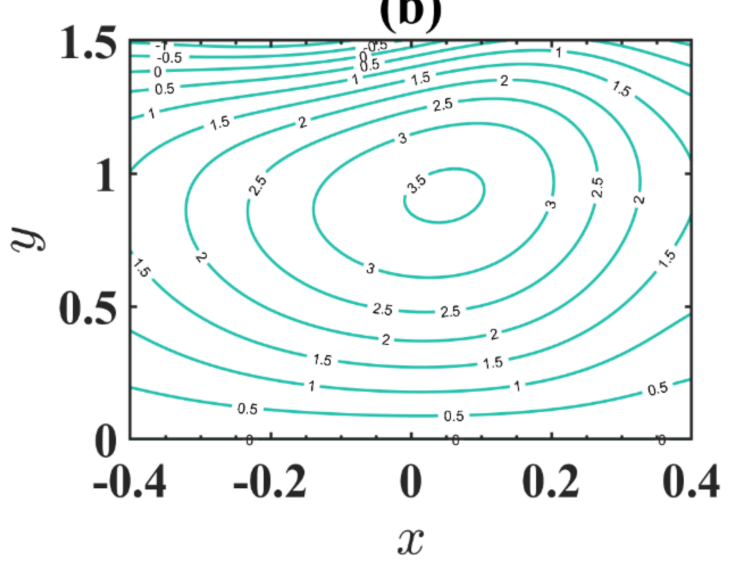

(d)

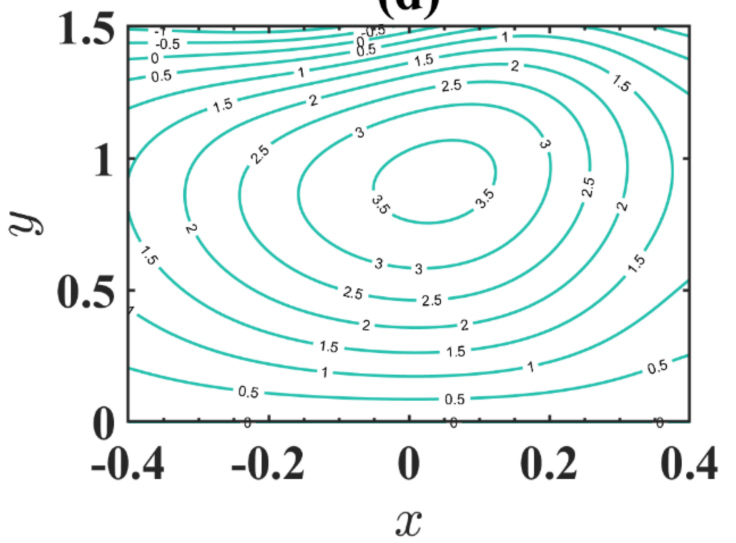

(f)

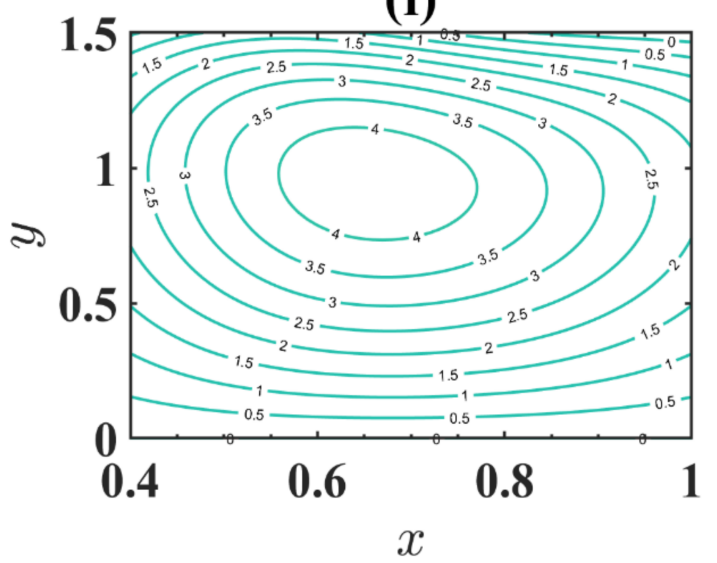

Figure 13. Streamlines for varying (a) $E_{1}=0.09, E_{2}=0.04, E_{3}=0.4, E_{4}=0.002, E_{5}=0.02,(\mathbf{b}) E_{1}=0.1, E_{2}=0.04$, $E_{3}=0.4, E_{4}=0.002, E_{5}=0.02,(\mathbf{c}) E_{1}=0.1, E_{2}=0.045, E_{3}=0.4, E_{4}=0.002, E_{5}=0.02,(d) E_{1}=0.1, E_{2}=0.045$, $E_{3}=0.45, E_{4}=0.002, E_{5}=0.02,(\mathbf{e}) E_{1}=0.1, E_{2}=0.045, E_{3}=0.45, E_{4}=0.006, E_{5}=0.02$, and (f) $E_{1}=0.1$, $E_{2}=0.045, E_{3}=0.45, E_{4}=0.006, E_{5}=0.2$.

\section{Conclusions}

This investigation describes the impact of electroosmotic properties, wall properties, and variable liquid properties on the peristaltic flow of the Jeffrey liquid in an inclined channel. The perturbation technique is utilized to obtain the solutions for velocity and temperature expressions. MATLAB programming is used to discusses the impact of critical terms over velocity, concentration, temperature, and streamlines. The outcomes of this 
paper have potential applications in both the industry and medical areas of research. Besides considering the slip and variable fluid properties in peristaltic circulation, physical conditions, such as an asymmetric/tapered uneven artery through a porous medium, can be applied in future research. The present investigation provides a fair theoretical approximation for future research in this direction. The significant primary outcomes of the current model are summed as follows:

- The impact of optimum electroosmotic velocity enhances the velocity profiles.

- $\quad$ Electroosmotic specification is a decreasing function of velocity.

- The increasing values of the Brinkman number and the non-uniform parameter enhance the velocity profiles.

- $\quad$ The Jeffrey term boosts the temperature and velocity profiles.

- The changeable viscosity and variable thermal conductivity boost the velocity and temperature profiles.

- The concentration profiles significantly diminish for more significant values of the Schmidt and Soret numbers.

- The influence of $E_{1}$ and $E_{2}$ enhances the velocity and temperature profiles for Newtonian fluids, and it decreases for $E_{3}, E_{4}$, and $E_{5}$.

- The size of the trapped bolus increases through an expansion in the estimation of changeable viscosity.

- Accumulation of streamlines decreases with an increase in maximum electroosmotic velocity.

- The number of enclosed boluses is augmented through a boost in the electroosmotic criterion.

Author Contributions: Conceptualization, C.R. and K.V.P.; methodology, C.R.; validation, H.B., G.M. and H.V.; investigation, C.R.; writing-original draft preparation, C.R., F.M.-O. and K.V.P.; writing—review and editing, I.E.S.; visualization, H.B., G.M. and H.V.; supervision, I.E.S. All authors have read and agreed to the published version of the manuscript.

Funding: This research received no external funding.

Conflicts of Interest: The authors declare no conflict of interest.

\section{Nomenclature}

$\begin{array}{ll}T_{a v} & \text { average temperature } \\ x, y & \text { axial and radial coordinates } \\ K_{B} & \text { Boltzmann constant } \\ B r & \text { Brinkmann number } \\ n_{0} & \text { bulk concentration } \\ z_{v} & \text { charge balance } \\ E c & \text { Eckert number } \\ E_{1}, E_{2}, E_{3}, E_{4} \& E_{5} & \text { elastic parameters } \\ e & \text { electronic charge } \\ m_{e} & \text { electroosmotic term } \\ S & \text { extra stress tensor } \\ U_{h s} & \text { Helmholtz-Smoluchowski velocity } \\ I & \text { identity tensor } \\ h & \text { length of the channel } \\ n_{1} & \text { mass per unit area } \\ m_{1} & \text { mass per unit surface } \\ P r & \text { Prandtl number } \\ P & \text { pressure } \\ R_{e} & \text { Reynold's number } \\ S c & \text { Schmidt number } \\ S r & \text { Soret number }\end{array}$




$\begin{array}{ll}t & \text { time } \\ u, v & \text { velocity components } \\ n_{2} & \text { viscous damping coefficient } \\ c & \text { wave speed } \\ \text { Greek Letters } & \\ \epsilon & \text { amplitude ratio } \\ \alpha & \text { angle of inclination } \\ \tau & \text { Cauchy stress tensor } \\ \Omega & \text { concentration } \\ \lambda_{D} & \text { Debye length } \\ \rho & \text { density } \\ \xi & \text { dielectric permittivity } \\ \tau & \text { elastic tension } \\ \phi & \text { electric potential } \\ \eta & \text { fluid flow parameter } \\ \lambda_{1} & \text { ratio of relaxation to retardation } \\ \lambda_{2} & \text { retardation time } \\ \dot{\gamma} & \text { shear rate } \\ \psi & \text { streamline } \\ \theta & \text { temperature } \\ \gamma & \text { thermal conductivity coefficient } \\ \rho_{e} & \text { total charge density } \\ \alpha_{2} & \text { variable thermal conductivity } \\ \alpha_{1} & \text { variable viscosity } \\ \lambda & \text { wave length } \\ & \end{array}$

\section{References}

1. Latham, T.W. Fluid Motions in a Peristaltic Pump. Ph.D. Thesis, Massachusetts Institute of Technology, Cambridge, MA, USA, 1996.

2. Raju, K.; Devantahan, R. Peristaltic transport of non-Newtonian fluid. Rheol. Acta 1972, 11, 170-178. [CrossRef]

3. Manjunatha, G.; Rajashekhar, C. Slip Effects on Peristaltic Transport of Casson Fluid in an Inclined Elastic Tube with Porous Walls. J. Adv. Res. Fluid Mech. Therm. Sci. 2018, 43, 67-80.

4. Vaidya, H.; Rajashekhar, C.; Manjunatha, G.; Prasad, K.V. Rheological Properties and Peristalsis of Rabinowitsch Fluid Through Compliant Porous Walls in an Inclined Channel. J. Nanofluids 2018, 8, 970-979. [CrossRef]

5. Manjunatha, G.; Rajashekhar, C.; Vaidya, H.; Prasad, K.; Makinde, O.D. Effects Wall Properties on Peristaltic Transport of Rabinowitsch Fluid through an Inclined Non-Uniform Slippery Tube. Defect Diffus. Forum 2019, 392, 138-157. [CrossRef]

6. Mebarek-Oudina, F.; Fares, R.; Aissa, A.; Lewis, R.; Abu-Hamdeh, N.H. Entropy and convection effect on magnetized hybrid nano-liquid flow inside a trapezoidal cavity with zigzagged wall. Int. Commun. Heat Mass Transf. 2021, 125, 105279. [CrossRef]

7. Shafiq, A.; Mebarek-Oudina, F.; Sindhu, T.N.; Abidi, A. A study of dual stratification on stagnation point Walters' B nanofluid flow via radiative Riga plate: A statistical approach. Eur. Phys. J. Plus 2021, 136, 1-24. [CrossRef]

8. Vajravelu, K.; Radhakrishnamacharya, G.; Radhakrishnamurty, V. Peristaltic flow and heat transfer in a vertical porous annulus, with long wave approximation. Int. J. Non-linear Mech. 2007, 42, 754-759. [CrossRef]

9. Srinivas, S.; Kothandapani, M. Peristaltic transport in an asymmetric channel with heat transfer-A note. Int. Commun. Heat Mass Transf. 2008, 35, 514-522. [CrossRef]

10. Ali, N.; Sajid, M.; Javed, T.; Abbas, Z. Heat transfer analysis of peristaltic flow in a curved channel. Int. J. Heat Mass Transf. 2010, 53, 3319-3325. [CrossRef]

11. Tanveer, A.; Hayat, T.; Alsaedi, A.; Ahmad, B. Heat Transfer Analysis for Peristalsis of MHD Carreau Fluid in a Curved Channel Through Modified Darcy Law. J. Mech. 2018, 35, 527-535. [CrossRef]

12. Ellahi, R.; Bhatti, M.M.; Vafai, K. Effects of heat and mass transfer on peristaltic flow in a non-uniform rectangular duct. Int. J. Heat Mass Transf. 2014, 71, 706-719. [CrossRef]

13. Iftikhar, N.; Rahman, A. Peristaltic flow of an Eyring Prandtl fluid in a diverging tube with heat and mass transfer. Int. J. Heat Mass Transf. 2017, 111, 667-676. [CrossRef]

14. Magesh, A.; Kothandapani, M. Heat and mass transfer analysis on non-Newtonian fluid motion driven by peristaltic pumping in an asymmetric curved channel. Eur. Phys. J. Plus 2021, 230, 1447-1464.

15. Warke, A.S.; Ramesh, K.; Mebarek-Oudina, F.; Abidi, A. Numerical Investigation of Nonlinear Radiation with Magnetomicropolar Stagnation Point Flow past a Heated Stretching Sheet. J. Therm. Anal. Calorim. 2021, 135, 533-549.

16. Rajashekhar, C.; Mebarek-Oudina, F.; Vaidya, H.; Prasad, K.V.; Manjunatha, G.; Balachandra, H. Mass and heat transport impact on the peristaltic flow of a Ree-Eyring liquid through variable properties for hemodynamic flow. Heat Transf. 2021, 50, 5106-5122. [CrossRef] 
17. Mittra, T.K.; Prasad, S.N. On the influence of wall properties and Poiseuille flow in peristalsis. J. Biomech. 1973, 6, 681-693. [CrossRef]

18. Srinivas, S.; Kothandapani, M. The influence of heat and mass transfer on MHD peristaltic flow through a porous space with complaint walls. Appl. Math. Comput. 2009, 213, 197-208.

19. Hayat, T.; Javed, M.; Hendi, A.A. Peristaltic transport of viscous fluid in a curved channel with com-plaint walls. Int. J. Heat Mass Transf. 2011, 54, 1615-1621. [CrossRef]

20. Eldesoky, I.M.; Abumandour, R.M.; Kamel, M.H.; Abdelwahab, E.T. The combined influences of heat transfer, complaint wall properties and slip conditions on the peristaltic flow through tube. SN Appl. Sci. 2019, 1, 897. [CrossRef]

21. Javed, M.; Naz, R. Peristaltic flow of a realistic fluid in a complaint channel. Phys. A Stat. Mech. Appl. 2020, 551, 123895. [CrossRef]

22. Nadeem, S.; Hayat, T.; Akbar, N.S.; Malik, M. On the influence of heat transfer in peristalsis with variable viscosity. Int. J. Heat Mass Transf. 2009, 52, 4722-4730. [CrossRef]

23. Sinha, A.; Shit, G.C.; Ranjit, N.K. Peristaltic transport of MHD flow and heat transfer in an asym-metric channel: Effects of variable viscosity, velocity slip and temperature jump. Alex. Eng. J. 2015, 54, 691-704. [CrossRef]

24. Nadeem, S.; Akbar, N.S. Influence of temperature dependent viscosity on peristaltic transport of a Newtonian fluid: Application of an endoscope. Appl. Math. Comput. 2010, 216, 3606-3619. [CrossRef]

25. Nadeem, S.; Akbar, N.S. Effects of temperature dependent viscosity on peristaltic flow of a Jeffrey-six constant fluid in a non-uniform vertical tube. Commun. Nonlinear Sci. Numer. Simulat. 2010, 15, 3950-3964. [CrossRef]

26. Vaidya, H.; Rajashekhar, C.; Manjunatha, G.; Prasad, K.V.; Makinde, O.D.; Sreenadh, S. Peristaltic Motion of Non-Newtonian Fluid with Variable Liquid Properties in a Convectively Heated Non-Uniform Tube: Rabinowitsch Fluid Model. J. Enhanc. Heat Transf. 2019, 26, 277-294. [CrossRef]

27. Chu, Y.-M.; Nazeer, M.; Khan, M.I.; Ali, W.; Zafar, Z.; Kadry, S.; Abdelmalek, Z. Entropy analysis in the Rabinowitsch fluid model through inclined Wavy Channel: Constant and variable properties. Int. Commun. Heat Mass Transf. 2020, 119, 104980. [CrossRef]

28. Rajashekhar, C.; Vaidya, H.; Prasad, K.V.; Tili, I.; Patil, A.; Nagathan, P. Unsteady flow of Rabinowitsch fluid peristaltic transport in a non-uniform channel with temperature-dependent properties. Alex. Eng. J. 2020, 59, 4745-4758. [CrossRef]

29. Vaidya, H.; Rajashekhar, C.; Manjunatha, G.; Prasad, K.V. Effect of variable liquid properties on peristaltic flow of a Rabinowitsch fluid in an inclined convective porous channel. Eur. Phys. J. Plus 2019, 134, 231. [CrossRef]

30. Vaidya, H.; Rajashekhar, C.; Mebarek-Oudina, F.; Animasaun, I.L.; Prasad, K.V.; Makinde, O.D. Combined effects of homogeneous and heterogeneous reactions on peristalsis of Ree-Eyring liquid: Application in hemodynamic flow. Heat Transf. 2021, 50, 2592-2609. [CrossRef]

31. Chakraborty, S. Augmentation of peristaltic microflows through electro-osmotic mechanisms. J. Phys. D Appl. Phys. 2006, 39, 5356-5363. [CrossRef]

32. Bruus, H. Theoretical Microfluidics; Oxford University Press: Oxford, UK, 2008; Volume 18, p. 346.

33. Ai, Y.; Yalcin, S.E.; Gu, D.; Baysal, O.; Baumgart, H.; Qian, S.; Beskok, A. A low-voltage nano-porous electroosmotic pump. J. Colloid Interface Sci. 2010, 350, 465-470. [CrossRef] [PubMed]

34. Wu, X.; Rajasekaran, P.R.; Martin, C.R. An Alternating Current Electroosmotic Pump Based on Conical Nanopore Membranes. ACS Nano 2016, 10, 4637-4643. [CrossRef] [PubMed]

35. Asandei, A.; Schiopu, I.; Chinappi, M.; Seo, C.H.; Park, Y.; Luchian, T. Electroosmotic trap against the electrophoretic force near a protein nanopore reveals peptide dynamics during capture and translocation. ACS Appl. Mater. Interfaces 2016, 8, 13166-13179. [CrossRef] [PubMed]

36. Bengtsson, K.; Robinson, N.D. A large-area, all-plastic, flexible electroosmotic pump. Microfluid. Nanofluid. 2017, 21 , 178. [CrossRef]

37. Huang, G.; Willems, K.; Soskine, M.; Wloka, C.; Maglia, G. Electro-osmotic capture and ionic discrimination of peptide and protein biomarkers with FraC nanopores. Nat. Commun. 2017, 8, 1-11. [CrossRef] [PubMed]

38. Chinappi, M.; Yamaji, M.; Kawano, R.; Cecconi, F. Analytical Model for Particle Capture in Nanopores Elucidates Competition among Electrophoresis, Electroosmosis, and Dielectrophoresis. ACS Nano 2020, 14, 15816-15828. [CrossRef]

39. Talapatra, S.; Chakraborty, S. Squeeze-Flow Electroosmotic pumping between charged parallel plates. Int. J. Fluid Mech. Res. 2009, 36, 460-472. [CrossRef]

40. Bandopadhyay, A.; Tripathi, D.; Chakraborty, S. Electroosmosis-modulated peristaltic transport in microfluidic channels. Phys. Fluids 2016, 28, 052002. [CrossRef]

41. Waheed, S.; Noreen, S.; Hussanan, A. Study of Heat and Mass Transfer in Electroosmotic Flow of Third Order Fluid through Peristaltic Microchannels. Appl. Sci. 2019, 9, 2164. [CrossRef]

42. Waheed, S.; Noreen, S.; Tripathi, D.; Lu, D. Electrothermal transport of third-order fluids regulated by peristaltic pumping. J. Biol. Phys. 2020, 46, 45-65. [CrossRef]

43. Noreen, S.; Waheed, S.; Lu, D.; Tripathi, D. Heat stream in electroosmotic bio-fluid flow in straight microchannel via peristalsis. Int. Commun. Heat Mass Transf. 2021, 123, 105180. [CrossRef]

44. Tripathi, D.; Prakash, J.; Reddy, M.G.; Misra, J.C. Numerical simulation of double diffusive convection and electroosmosis during peristaltic transport of a micropolar nanofluid on an asymmetric microchannel. J. Therm. Anal. Calorim. 2021, 143, 2499-2514. [CrossRef] 